\title{
ATORES PERIFÉRICOS NA SOCIEDADE CIVIL Redes e centralidades de organizações em São Paulo
}

\author{
Adrián Gurza Lavalle \\ Graziela Castello \\ Renata Mirandola Bichir
}

Introdução

A existência de heterogeneidade ornou-se aos poucos esclarecimento distintivo dos balanços da literatura sobre a sociedade civil. ${ }^{1} \mathrm{O}$ esclarecimento, cada vez mais comum no debate dos anos recentes, visa às compreensões demasiadamente estilizadas e normativamente sobrecarregadas de sociedade civil que se alastraram vertiginosamente ao longo dos anos de 1990 no Brasil e pelo mundo afora. ${ }^{2}$ Se considerado o pano de fundo contra o qual se projeta o reparo, firmar a heterogeneidade dos atores coletivos englobados na rubrica "sociedade civil" traz consigo conseqüências cognitivas não triviais, pois coloca em xeque o pressuposto de um princípio de unificação simbolicamente compartilhado por uma miríade de entidades de

Artigo recebido em marco/2008

Aprovado em setembro/2008 perfis assaz diversos. Entretanto, a noção de heterogeneidade carece de estatuto analítico em si e, na verdade, constitui ponto de partida útil se, e apenas se, animar caracterizações capazes de mostrar e elaborar analiticamente as formas em que essa heterogeneidade se ordena e opera. Assim, filões completos de questões sociologicamente ricas e passíveis de problematização sob pressuposto da heterogeneidade aguardam tratamento sistemático. Pouco sabemos, por exemplo, das hierarquias internas e da capacidade de ação desiguais das organizações civis, da sua diferenciação funcional e das clivagens políticas e conflitos internos, em suma, do modus operandi da sociedade civil.

As lacunas no conhecimento das dinâmicas internas do universo das organizações civis não passaram despercebidas sequer entre aqueles que mais decisivamente contribuíram para alimentar a variante enfática da sociedade civil - para dizê-lo com fórmula cunhada por Sergio Costa. ${ }^{3}$ Antes, 
seus autores mais lúcidos reagiram, não sem certo estranhamento, contra os excessos simplificadores e maniqueístas dos usos da categoria sociedade civil (Walzer, 1992), bem como assinalaram as ambigüidades analíticas que a sua própria redefinição conceitual tinha deixado em pé. De modo emblemático, Andrew Arato (1995), em texto apenas dois anos posterior à sua influente obra publicada com Jean Cohen, atentou para os efeitos de escurecimento da categoria "sociedade civil" sobre a variedade de grupos e movimentos por ela englobados. Mais: reconfirmou de modo incisivo aquilo que sua alentada atualização teórica da categoria "sociedade civil" tinha processado e construído de modo profuso, a saber, "a unidade da sociedade civil só é óbvia quando considerada de uma perspectiva normativa" (Arato, 1995, p. 21; ver Cohen e Arato, 1992, pp. 395-475). Não raro, tal perspectiva normativa foi projetada como diagnóstico da ação coletiva existente em diferentes contextos sem mediações analíticas nem re-especificações conceituais sensíveis às exigências da pesquisa empírica.

Este artigo inscreve-se nos esforços da literatura dos últimos anos no sentido de avançar simultaneamente na produção de conhecimento empírico acerca dos alcances, dos fatores condicionantes e das lógicas que orientam a ação dos diferentes tipos de atores da sociedade civil, bem como na decantação de distinções analíticas capazes de alimentar a reflexão no plano da teoria positiva, complementando os resultados e a análise apresentados em Gurza Lavalle, Castello e Bichir (2007). Assumese que teorias positivas são passíveis de diversos usos normativos e, nesse sentido, não excluem nem substituem a teoria normativa, mas informam-na de modo a torná-la menos ingênua e a favorecer sua aderência às questões trazidas pela sistematização e acumulação de conhecimento empírico do mundo. Hoje na literatura ensejam-se interpretações e pesquisas que, em flancos diversos, revelam elementos da ordenação e da operação dos atores englobados na categoria sociedade civil sob idéias como, entre outras, "projeto político", "trajetórias de lideranças", "desenho institucional" de instâncias de participação, accountability interna, "representação presuntiva", "ecologia associativa" e "redes de atores sociais". ${ }^{4}$ Especificamente, o uso da idéia de "redes" deslocou-se progressivamente de um registro pioneiro de índole metafórica - no qual se atentava ora para a porosidade e a fluidez das fronteiras dos movimentos sociais, ora para estratégias de atuação distintivas de determinados atores; notadamente das ONGs - para a análise de redes como estratégia de abordagem munida de metodologia e pressupostos analíticos próprios. Os resultados aqui apresentados fazem parte desse deslocamento (ver Gurza Lavalle, Castello e Bichir, 2004).

As vantagens de se utilizar, strictu senso, uma abordagem relacional para lidar com ação coletiva organizada são bem conhecidas (Diani e McAdam, 2003). Há, todavia, algumas vantagens adicionais quando a análise de redes é introduzida no terreno do estudo empírico de organizações civis. Tal como observado por Bebbington (2002), em exame dos vieses metodológicos que solapam a construção de conhecimento sobre as ONGs na América Latina, as análises empíricas nesta área não apenas costumam privilegiar o próprio ator como unidade de análise, mas não raro elevam-no ao estatuto de principal produtor de conhecimento sobre si próprio e sobre o campo em que se encontra inserido. Abordagens relacionais, como a empregada neste artigo, permitem interpretações estruturais das capacidades e das ações dos atores, ou seja, não são baseadas na autocompreensão e racionalização de si próprios, mas na sua posição (objetivada) dentro de redes de relações que condensam e condicionam a lógica e os alcances da sua atuação.

Em trabalho de recente publicação (Gurza Lavalle, Castello e Bichir, 2007) foram identificados empiricamente e examinados, mediante análise de redes, os atores mais centrais no universo das organizações civis paulistanas, ou seja, os grandes protagonistas com maior capacidade de ação e escolha na rede. Nestas páginas, focamos a atenção nos atores menos centrais e naqueles marginais ou francamente periféricos desse universo; por conseguinte, atores situados em posições desfavoráveis e cujo tratamento na literatura tem sido igualmente secundário. Exploram-se os resultados de survey realizado durantes seis meses de trabalho de campo na cidade de São Paulo, no ano de 2002, no qual foram entrevistadas mais de duzentas organizações civis, gerando um banco de dados com mais de setecentos atores diferentes, e milhares de relações. ${ }^{5}$

Sabemos que o universo das organizações civis paulistanas apresenta uma notável conectividade difusa. Ademais, as relações entre seus atores 
são acentuadamente hierarquizadas, e aqueles com maior protagonismo - a saber, organizações populares, articuladoras e ONGs - acumulam vantagens estruturais de modo sistemático (Gurza Lavalle, Castello e Bichir, 2007). Isso gera desigualdades fortes quanto às capacidades de atuação e escolha dos diferentes tipos de organizações civis. Também, foi mostrada a existência de padrões relacionais diferenciados entre os atores centrais e o restante da rede, apontando para uma diferenciação funcional clara. Não cabe aqui descrever tal diferenciação nem os principais achados dessa análise acerca das especificidades dos três tipos de atores examinados. Atenta-se apenas para a ausência de caracterização complementar para os atores menos relevantes ou francamente marginais: quais são os atores periféricos no universo das organizações civis? Como lidam com sua condição periférica? Ou, melhor: desenvolvem estratégias de ação de modo a compensá-la? Que atores desempenham funções de intermediação entre os nichos periféricos e centrais da rede? Enfim, qual a diferenciação funcional entre atores marcados pela limitação de recursos relacionais e, em princípio - apenas em princípio , condenados à invisibilidade e incapacidade de fazer ouvir sua voz?

Tais perguntas encontram respostas - por vezes, contra-intuitivas - nas páginas que se seguem. Os resultados da análise de redes mostram que associações comunitárias e associações de bairro guardam as posições mais periféricas, antecedidas por entidades assistenciais e fóruns, cuja centralidade é intermediária. Cumpre frisar desde já que a desigualdade posicional ou a presença de organizações relegadas a nichos marginais não decorre da análise de redes em si, mas constitui achado empírico da pesquisa. ${ }^{6}$ Se os grandes protagonistas do universo das organizações civis caracterizam-se pela sobreposição de vantagens estruturais, achado inverso era esperável para as entidades não-centrais, e foi confirmado.

Porém, entidades ocupam posições periféricas e intermediárias equivalentes por motivos distintos e no cumprimento de vocações funcionais diferentes. Assim, a interpretação integrada dos resultados permite avançar para além da mera constatação das hierarquias posicionais, alimentando elaborações nuançadas do modo de operação dessas entidades. A seção maior deste artigo dedica-se à elaboração de tal interpretação integrada e à extra- ção de conclusões em relação ao estado atual do conhecimento sobre as organizações civis em questão. Em traços gerais, cabe apontar que malgrado sua posição relacional desprivilegiada, as associações de bairro não permanecem confinadas à microterritorialidade, mas atingem com certa facilidade os locais mais centrais da rede e as oportunidades de ação e escolha a eles associados; nada semelhante ocorre, todavia, com as associações comunitárias. Enquanto as primeiras beneficiam-se dos recursos canalizados pelas entidades assistenciais e, a um só tempo, da possibilidade de incidir na definição de prioridades e recursos públicos mediante suas relações com atores altamente centrais, as associações comunitárias permanecem isoladas e presas a um universo de relações que tende a se esgotar nos seus próprios membros. Por sua vez, as organizações civis intermediárias (fóruns e entidades assistenciais), quando examinadas do ponto de vista dos seus padrões relacionais, permitem esboçar os traços de uma divisão do trabalho ou diferenciação funcional no universo das organizações civis não-centrais, na qual elas desempenham o papel de atores-ponte (denominação aqui preferida em relação a termos comuns na literatura como broker e gatekeeper). ${ }^{7}$ A despeito das diferenças entre entidades assistenciais e fóruns, ambos os tipos de entidades não apenas conectam entidades centrais e periféricas em mão dupla - sendo que as entidades centrais inclusive são intermediadas por elas -, como também apresentam padrões de relacionamento marcadamente heterófilos, quer dizer, encontramse entre os atores que menos investem na construção de vínculos com organizações civis do seu mesmo tipo.

Os diversos tipos de atores e o conhecimento estabelecido na literatura sobre eles serão abordados nas próximas seções e, em seguida, serão tratadas brevemente a estratégia de análise relacional aqui utilizada e a metodologia correspondente. A síntese geral dos resultados em termos de posições periféricas e intermediárias ocupadas pelos diferentes tipos de organizações civis ocupa a antepenúltima seção. A interpretação das especificidades funcionais e das estratégias relacionais dos quatro tipos de organizações incorpora a representação visual das redes em sociogramas e a combina com a leitura integrada das medidas de centralidade e coesão sumarizadas na seção anterior. $\mathrm{O}$ artigo encerra com breve comentário final. 


\section{Atores periféricos e atores-ponte}

O estudo das organizações civis impõe o desafio de desenvolver caracterizações capazes de organizar de modo coerente a complexidade e a diversidade inerentes a esses atores. Conforme apresentado em Gurza Lavalle, Castello e Bichir (2007), as organizações civis não foram classificadas com base em suas autodefinições, senão conforme critérios objetivos de duas ordens: a relação com seus beneficiários e o perfil das atividades normalmente realizadas. No primeiro caso, (i) o conjunto dos beneficiários encarna uma unidade restrita e concreta ou geral e abstrata (por exemplo, os moradores do bairro ou os cidadãos, respectivamente), (ii) cujos componentes são indivíduos, organizações e atores coletivos, ou segmentos da população (iii) concebidos como membros ou sócios, como público alvo, ou como a comunidade. No segundo caso, a cada tipo de associação corresponde (i) uma estratégia de atuação distintiva e (ii) combinações excludentes de atividades orientadas para a reivindicação e a mobilização, para o fornecimento de serviços, para a organização popular, ou para a intermediação entre o governo e os beneficiários. $\mathrm{O}$ problema contornado mediante a adoção de parâmetros formais, é claro, não diz respeito à criação de novas denominações ou classificações imaginativas, mas à definição e à introdução de critérios de objetivação capazes de equacionar as dificuldades inerentes à autoclassificação.

Os atores que constam do Quadro 1 foram qualificados como periféricos ou ponte em termos relacionais a partir dos resultados da pesquisa, evitando intencionalmente a qualificação dedutiva ou apriorística da sua posição no universo das organizações civis. Nesse quadro é possível apreciar a composição da amostra, bem como a sistematização da tipologia no caso do atores analisados e alguns exemplos das organizações civis paulistanas classificadas em cada tipo. Os critérios adotados para colher a amostra serão brevemente analisados em seção específica mais adiante. As associações de bairro e as entidades assistenciais apresentam maior peso na amostra dos tipos analisados, constituindo $17 \%$ em cada caso. Por sua vez, fóruns e associações comunitárias registram menos da metade do peso das primeiras. A categoria "Demais Atores" não é residual: de um lado, adiciona os resultados, separadamente calculados, de três tipos de organizações civis definidos empiricamente conforme os mesmos critérios, e cujas posições na rede são, em contraponto, as mais centrais; de outro, os resultados agregados de organizações populares, ONGs e articuladoras - os três grandes tipos de organizações civis protagonistas na rede - funcionarão como categoria de referência na ordenação de parte dos dados a serem examinados. ${ }^{8}$

Quadro 1

Tipologia dos Atores Periféricos e Ponte

\begin{tabular}{|c|c|c|c|c|c|}
\hline Categoria & Freqüência & $\%$ & Beneficiários & Atividades & Exemplos \\
\hline $\begin{array}{l}\text { Associações } \\
\text { de Bairro }\end{array}$ & 34 & 17 & $\begin{array}{l}\text { (i) Unidade Real } \\
\text { (ii) Indivíduos } \\
\text { (iii) Membros ou Comuni- } \\
\text { dade }\end{array}$ & $\begin{array}{l}\text { (i) Projeção de demandas locais e aju- } \\
\text { da mútua } \\
\text { (ii) Organização popular; reivindicação/ } \\
\text { mobilização; fornecimento de serviços }\end{array}$ & $\begin{array}{l}\text { Sociedades de Amigos de Vila Sa- } \\
\text { brina; Sociedade Amigos de Vila Al- } \\
\text { pinas; União dos Moradores do Par- } \\
\text { que Bristol }\end{array}$ \\
\hline $\begin{array}{l}\text { Associações } \\
\text { Comunitárias }\end{array}$ & 17 & 8 & $\begin{array}{l}\text { (i) Unidade Real } \\
\text { (ii) Indivíduos } \\
\text { (iii) Membros }\end{array}$ & $\begin{array}{l}\text { (i) Ajuda mútua } \\
\text { (ii) Fornecimento de serviços }\end{array}$ & $\begin{array}{l}\text { Clubes de Mães Coração do Amor; } \\
\text { Espaço Cultural São Mateus; Assis- } \\
\text { tência de Deficientes Físicos de } \\
\text { Sapopemba }\end{array}$ \\
\hline $\begin{array}{l}\text { Entidades } \\
\text { Assistenciais }\end{array}$ & 34 & 17 & $\begin{array}{l}\text { (i) Unidade Real ou Abstrata } \\
\text { (ii) Indivíduos } \\
\text { (iii) Público Alvo }\end{array}$ & $\begin{array}{l}\text { (i) Prestar assistência definida por vul- } \\
\text { nerabilidades } \\
\text { (ii) Fornecimento de serviços }\end{array}$ & $\begin{array}{l}\text { Lar Altair Martins; Centro Social } \\
\text { Leão XIII; Serviço Social Perseve- } \\
\text { rança }\end{array}$ \\
\hline Fóruns & 13 & 6 & $\begin{array}{l}\text { (i) Unidade Real ou Abstrata } \\
\text { (ii) Organizações e Atores } \\
\text { Coletivos } \\
\text { (iii) Membros ou Comunidade }\end{array}$ & $\begin{array}{l}\text { i) Tematizar publicamente problemas; } \\
\text { articular atores e iniciativas sociais. } \\
\text { ii) Reivindicação/ mobilização; inter- } \\
\text { mediação }\end{array}$ & $\begin{array}{l}\text { Fórum Municipal de Saúde, Fórum } \\
\text { DCA; Fórum Lixo e Cidadania da } \\
\text { Cd. De SP }\end{array}$ \\
\hline $\begin{array}{l}\text { Demais } \\
\text { atores }\end{array}$ & & & & & $\begin{array}{l}\text { Articuladoras, ONGs, Organizações } \\
\text { Populares }\end{array}$ \\
\hline
\end{tabular}


Por fim, e visto que toda tipologia leva à reagrupação de resultados em subconjuntos, caberia perguntar se eventuais agrupações seguindo outros critérios autorizariam leituras como aquela que será apresentada nestas páginas. A redução de casos (organizações civis) a clusters (tipologia) costuma obedecer a dois critérios básicos: ou há boas razões analíticas para optar por uma forma específica de agrupação ou análises empíricas mediante técnicas de cluster mostram padrões empíricos consistentes - independentemente de eles corresponderem ou não a expectativas analíticas claramente formuladas. Neste caso, a agrupação responde a ambos os critérios. De um lado, a tipologia de organizações civis constitui uma síntese do conhecimento acumulado sobre esse universo de atores e agiliza a interlocução com atores e autores interessados nas questões aqui analisadas; de outro, testes empíricos não revelaram outras formas de agrupação consistentes.

\section{A caracterização dos atores na literatura}

Diversos elementos têm animado o reconhecimento da heterogeneidade da sociedade civil. Primeiro, as assimilações locais do debate teórico internacional acabaram por ceder passo à multiplicação de anomalias e insuficiências em contextos nacionais como na Índia (Tandon e Mohanty, 2003; Oommen, 2004) ou em diversos países da América Latina (Dagnino, Olvera e Panfichi, 2006; Olvera, 2003; Avritzer, 2004). No Brasil, a intensa inovação em experiências participativas para o desenho e a supervisão de políticas públicas exigiu uma reformulação dos termos do debate no sentido de se pensar a relação entre o Estado e a chamada sociedade civil (por exemplo, Perissinoto, 2004; Dagnino, 2002; Texeira, 2002; Gurza Lavalle, Acharya e Houtzager, 2005). Segundo, outras agendas de pesquisa, por certo menos influentes, debruçaram-se sobre o estudo das organizações civis em registro teoricamente menos sobredeterminado. Algumas das reconstruções mais ricas e nuançadas da difícil sedimentação de identidades no interior do universo das organizações civis foram elaboradas sob a agenda de pesquisa do terceiro setor (por exemplo, Landim, 1998; Fernandes, 2002). Isso sem esquecer a produção de conhecimento e documentação sobre as transformações internas das organiza- ções civis elaboradas pelos próprios atores sociais, céticos perante um mundo acadêmico que, nos anos de 1980, cultivou exíguo interesse pelos fenômenos de invenção e renovação organizacional emergentes no plano da ação coletiva institucionalizada - notadamente as ONGs (Landim, 2002).

O trabalho desenvolvido nas últimas décadas por essas e outras perspectivas para apreender a profusão de "projetos parcelares" e "microdiscursos" (Carvalho, 1998, p. 85), o pragmatismo e as práticas diversas da miríade de entidades que compõem o universo das organizações civis constitui o conhecimento disponível para caracterizar os diferentes tipos de organizações aqui estudadas. Nesse sentido, a caracterização dos tipos de organizações civis, nos parágrafos que se seguem, espelha com maior ou menor fidelidade o estado da literatura.

As associações de bairro exercem atividades relacionadas com demandas urbanas específicas conforme um princípio de identidade territorial e, nesse sentido, trabalham em e para uma comunidade. $\mathrm{Na}$ literatura dos anos de 1980, elas foram pensadas no registro dos movimentos sociais, especificamente como movimentos de bairro (Singer e Brant, 1980, pp. 83-107), alinhados dentro do campo dos movimentos populares (Fernandes, 2002, pp. 45-46), isto é, distintos, pela sua origem socioeconômica, das associações de amigos de bairro ou das associações de moradores de classes médias, que também passaram por processos de ampliação e politização das suas atividades no contexto das lutas pela transição (Boschi, 1987; Singer e Brant, 1980, pp. 85-93). Autoconstrução, conquista de creches e postos de saúde, ocupação e legalização de terrenos, ampliação e aprimoramento do transporte público, bem como um leque de reivindicações de infra-estrutura urbana básica, definiram e continuam a definir, embora de modo menos dramático, a pauta de reivindicações das associações de bairro; pauta impulsionada mediante a mobilização e a pressão da população sobre as instâncias governamentais de tomada de decisões. Essas associações perderam centralidade no debate acadêmico dos anos de 1990, pois suas reivindicações eminentemente materiais ou distributivas, sua baixa visibilidade e suas capacidades mínimas para disputar a agenda pública tornaram-nas pouco palatáveis às exigências normativas da perspectiva da "nova sociedade civil" que definiu o teor do debate nos anos de 1990 (Gurza Lavalle, 2003). 
Por motivos semelhantes, as associações comunitárias tampouco foram objeto de análise da perspectiva da nova sociedade civil. Mais: pelo seu caráter extremamente diverso e localizado, sequer constaram entre os atores privilegiados pelos estudos de caso da literatura sobre movimentos sociais. Há, é claro, uma exceção notável na literatura, a saber, as comunidades eclesiais de bases (CEBs); no entanto, o retraimento da intervenção social da Igreja a partir do final dos anos de 1980 trouxe consigo uma perda acentuada do protagonismo das CEBs (Doimo, 1995). Ainda hoje, parte das associações comunitárias - notadamente, Centros da Juventude (CJs), grupos de terceira idade ou grupos culturais - mantém uma conexão direta ou indireta com o trabalho paroquial e pastoral da Igreja Católica (Doimo, 2004). Em termos muito gerais, as associações comunitárias respondem ao velho conceito de sociedades mutualistas ou de ajuda mútua (Fernandes, 2002). Nesse sentido, seus membros são simultaneamente os beneficiários e os agentes do trabalho desenvolvido pela entidade; eles constituem uma comunidade ou encontram-se inseridos numa comunidade maior, cuja lógica pode ser ou não de índole territorial. Embora de modo pouco freqüente, é possível encontrar caracterizações mais específicas na literatura para além do mutualismo: microterritorialidade ou microlocalização associadas a espaços comunicativos primários, pouca visibilidade e trabalho voluntário (Carvalho, 1998, pp. 86-87).

Bastante conhecidas e até há pouco tempo incontroversas, as entidades assistenciais exercem fundamentalmente trabalhos de prestação de serviços e assistência direta ao público para o qual trabalham. Suas feições distintivas são pacíficas na literatura, em que costumam aparecer sob combinações com ênfases diferenciadas de quatro elementos recorrentes: ethos cristão, prestação de serviços de índole assistencial, atendimento dos segmentos mais vulneráveis da população e financiamento provindo do setor privado - não raro mediante a figura da fundação empresarial (Carvalho, 1998, p. 87; Landim, 2002). Herdeiras da tradição filantrópica centenária para lidar com a questão social, as entidades de assistência estiveram na origem das primeiras fórmulas de previdência pública adotadas no Brasil e na América Latina (Fleury, 1994) e também definiram parte importante do repertório de opções associativas disponíveis no século XIX e primeiro terço do XX, ordenado pela força de gravitação da igreja católica (Avritzer, 1997). O perfil mais tradicional das entidades filantrópicas, embora caracterizado em parte nada desprezível da literatura sob a suspeição de um halo pré-moderno e conservador, é consensual. Contudo, a história recente do Brasil teria animado deslocamentos polêmicos no sentido de uma espécie de "onguização" das entidades assistenciais, levando-as a abandonar progressivamente sua tônica caritativa e apolítica para assumir uma maior politização e publicitação de seus trabalhos e demandas, bem como à adoção de discursos cifrados no registro dos direitos e da cidadania (Landim, 2002, pp. 32-36; Landim, 1998; Coelho, 2000, p. 64; Paz, 2005, pp. 18-19).

Os fóruns são instâncias de coordenação da ação e de agregação de interesses de organizações da sociedade civil agrupadas por afinidades temáticas ou, de modo mais preciso, funcionam como espaços de encontro e coordenação periódica que permitem adensar agendas e pautar a atuação do atores que neles participam. Duas considerações permitem classificar os fóruns como organizações civis: primeiro, em que pese seu caráter periódico, possuem um grau de institucionalização suficiente para impedir que seu funcionamento se torne esporádico; segundo, constituem uma peça importante da construção institucional das próprias organizações civis - peça especialmente adequada para o desenvolvimento e a sustentação do trabalho em redes temáticas. Dada sua orientação temática, fóruns desempenham papel relevante na definição e na coordenação de prioridades para os chamados conselheiros da sociedade civil que atuam nos conselhos gestores de políticas que, por sua vez, constituem de longe o arranjo institucional deliberativo privilegiado na literatura - junto com o orçamento participativo. Contudo, salvo raras exceções (por exemplo, Reis e Freire, 2002) os fóruns não têm sido objeto de estudo com dignidade própria.

\section{Análise relacional e survey}

Para analisar os padrões de relacionamento das organizações civis acima apresentadas, utilizamos a metodologia de análise de redes sociais, seguindo a discussão apresentada em maior detalhe em outros trabalhos (Gurza Lavalle, Castello e Bichir, 2007, e 2008). Aqui, serão apenas explicitados alguns ele- 
mentos da análise relacional e do survey indispensáveis para o acompanhamento da análise e da argumentação desenvolvidas nas próximas seções.

A análise de redes sociais assume como premissa a importância dos laços sociais como elementos que estruturam a vida social, Nesse sentido, a unidade de análise utilizada são as relações estabelecidas entre pessoas e entre entidades, e não os indivíduos ou organizações em si e sequer seus atributos. Como estratégia analítica, situa-se em plano cognitivo intermediário, trazendo consigo mudanças de perspectiva tanto na compreensão do plano macro (isto é, sociedade/sociedade civil) como do micro (isto é indivíduos/organizações civis) (Emirbayer, 1997). É importante destacar que, a rigor, a análise de redes sociais não constitui uma teoria e tampouco um conjunto de técnicas estatísticas complexas, mas uma estratégia analítica passível de utilização à luz de diferentes perspectivas conceituais e teóricas.

Em termos gerais, um ator periférico no interior de uma determinada rede é aquele que: conta com menor densidade de relacionamentos, sendo que muitas dessas relações são locais e homofílicas ou seja, tendem a ocorrer entre atores de características similares -; dispõe de baixa capacidade de mobilização e coordenação da ação de outras organizações civis; apresenta relevância marginal nas estratégias relacionais de outros atores e, não raro, guarda relações muito assimétricas com as organizações civis mais centrais, das quais depende para ter seus interesses representados e suas demandas escaladas a instâncias de deliberação e/ou decisão supralocais. Em suma, os atores periféricos no universo das organizações civis ocupam nichos específicos, tendem a desenvolver uma atuação bastante localizada e são fortemente dependentes das relações que estabelecem com os demais atores especialmente os mais centrais -, objetivando alcançar outros espaços na rede para ter acesso a informações, fontes de financiamento, incidência na tomada de decisões públicas etc. Assim como ocorre no caso das organizações com papel protagônico, os modos de inserção das organizações civis periféricas em um universo maior de relações moldam suas possibilidades de ação, pois os padrões de vinculação estabelecidos por cada tipo de organização civil com os demais e entre si estruturam complexas redes que, simultaneamente, abrem possibilidades de interação e constrangem alternativas.
A caracterização do perfil geral dos tipos de atores periféricos foi obtida por meio da utilização de medidas de centralidade e coesão, ${ }^{9}$ seguindo os mesmos procedimentos empregados no entendimento dos padrões de relacionamento das organizações civis centrais (Gurza Lavalle, Castello e Bichir, 2007). Grosso modo, as medidas de centralidade foram utilizadas para destacar a posição relativa de cada um dos atores considerados, identificando formas de hierarquização relacional das organizações civis de modo a examinar entidades não-centrais ou sem protagonismo no universo das organizações civis como um todo. $\mathrm{Na}$ análise, procurou-se identificar as organizações da sociedade civil que funcionam como referências no conjunto das organizações (número de vínculos recebidos - indegree) e aquelas caracterizadas por citar muitos parceiros (número de vinculos enviados - outdegree); ${ }^{10}$ as capacidades de intermediação (betweeness) e articulação de diferentes subredes; o grau de proximidade entre tipos de organizações civis (closenness) e a assimetria das relações existentes entre eles, aferindo a dependência produzida por certas entidades sobre outras (power). Procurou-se diferenciar, ainda, as organizações que lançam mais vínculos daquelas que são preponderantemente receptoras de vínculos, apresentando diferentes tipos de influência (influence); bem como, destacar as organizações com maior acesso à informação (information) no interior da rede, isto é, ao controle de certos fluxos preferenciais entre o conjunto de relações disponíveis. Além dessas medidas de centralidade, foram calculadas algumas medidas de coesão, visando a incorporar à análise as distâncias existentes entre cada um dos atores (geodesic distan$c e$ ), o número de atores que podem ser alcançados no interior da rede (reachability) e a disponibilidade de caminhos curtos para alcançá-los (count geodesic).

Considerando a complexidade estatística de algumas das medidas utilizadas e seu valor comparativo, optou-se por apresentar resultados simplificados, reportando apenas a hierarquia observada entre as organizações civis quanto à sua centralidade. As denominações técnicas das medidas também foram simplificadas. Além disso, para facilitar a compreensão dos resultados, são incorporadas as representações gráficas (sociogramas) das redes internas de cada tipo de organização civil aqui abordado. É importante ressaltar que os padrões estruturais de inserção dos diferentes tipos de organizações civis na rede foram construídos após a análise 
integrada de todas as medidas geradas, e não com base em medidas isoladas - as quais carecem de sentido se consideradas de modo independente. Cumpre advertir que os valores apresentados são relativos, ou seja, seu parâmetro é comparativo e reside nos diferentes valores internos das redes analisadas, não correspondendo a quaisquer valores absolutos ou externos.

A análise de redes aqui apresentada baseia-se em informações obtidas por meio de entrevistas realizadas com 202 organizações civis, em pesquisa realizada no município de São Paulo em 2002. ${ }^{11}$ Ao todo, as entrevistas geraram um total de 741 atores diferentes citados e 1.293 relações diretas levantadas. Como cada entidade entrevistada pôde citar até cinco relações em ordem de importância ou as mais próximas para diferentes tipos de entidades, as redes examinadas nestas páginas representam a malha mais densa de relações existentes entre as organizações civis paulistanas pesquisadas, e não a totalidade de vínculos existentes. O universo das entidades pesquisadas não foi definido a priori, mas empiricamente como base nas cadeias de referências fornecidas a partir de dezesseis pontos de entrada pelos atores entrevistados; referências colhidas em campo por meio da técnica bola de neve (snowball) - bastante utilizada em análises de redes sociais (Scott, 1992).

\section{Padrões de relacionamento das organizações civis periféricas}

Esta seção apresenta de modo sintético os principais resultados encontrados na análise dos padrões de relações entre as diversas organizações civis. As relações foram examinadas a partir de três ângulos ou recortes analíticos: i) identificação do papel desempenhado pelos tipos de entidades na rede como um todo ou no conjunto das organizações civis; ii) análise das formas de relacionamento que as organizações civis de cada tipo estabelecem entre si; iii) detecção de vínculos preferenciais entre os diferentes tipos de organizações civis. Cada recorte apresenta contribuições específicas para o entendimento das dinâmicas de funcionamento das organizações civis. A descrição geral aqui apresentada é seguida, na próxima seção, por interpretação do significado das posições estruturais de cada tipo de organização civil.
Com base em análises anteriores (Gurza Lavalle, Castello e Bichir, 2007), sabemos que o universo das organizações civis paulistanas é bastante estratificado, isto é, que as organizações estabelecem entre si relações hierárquicas, sujeitas a uma diferenciação funcional clara, sendo que organizações populares, articuladoras e ONGs desempenham papéis de protagonistas. Cabe agora analisar como as organizações civis periféricas e intermediárias inserem-se nesse universo.

Os resultados são sintetizados em três tabelas, uma para cada recorte analítico. Nas duas primeiras, os dados são porcentagens que exprimem as posições relativas de cada tipo de entidade em cada uma das medidas. ${ }^{12}$ As porcentagens foram calculadas em relação aos resultados dos três tipos mais centrais de entidades - organizações populares, ONGs e articuladoras -, agrupadas na categoria "demais autores". A média desses três tipos serve, assim, como parâmetro de comparação. ${ }^{13}$ Valores positivos indicam que, nessa medida, a entidade em questão tem um resultado melhor do que a média das entidades mais centrais. Valores negativos, pelo contrário, indicam resultados inferiores aos apresentados pelas organizações civis centrais. Os valores não possuem significado em si, mas permitem examinar as posições relativas das entidades estudadas. A maior parte dos dados tem valores negativos, isto é, os resultados apontam quão piores são os resultados desses atores. A lógica dessas tabelas é simples, mas seu significado, numa primeira leitura, pode parecer contra-intuitivo: valores negativos elevados são piores que valores negativos baixos, pois indicam que uma entidade é mais periférica. Na terceira tabela trata-se de um ranking simples, e os números exprimem apenas uma relação de ordem para cada ator nas medidas calculadas. Como são seis os tipos de atores analisados, o ranking de cada medida posiciona o respectivo ator entre um e seis.

$\mathrm{Na}$ Tabela 1 nota-se que todas as entidades aqui consideradas apresentam, via de regra, posições relativas inferiores às das organizações civis centrais em termos de centralidade e, quase sempre, de coesão. Por isso a caracterização de "atores periféricos", peculiarmente no caso das associações comunitárias, cujas posições são as piores em quase todas as medidas contempladas. $\mathrm{Na}$ "periferia" do campo societário estão localizadas não apenas as associações comunitárias, mas também as asso- 
ciações de bairro devido à sua relativa irrelevância para os outros atores - conforme mostrado na Tabela 3. Ambos os tipos de entidades mostramse fortemente dependentes dos vínculos estabelecidos com atores mais centrais. Em um segundo pla- no há entidades com posições intermediárias: os fóruns e as entidades assistenciais, que também possuem baixa centralidade, mas se destacam por serem procuradas e, conforme será visto, por atuarem como atores-ponte.

Tabela 1

Centralidade e Coesão da Rede Segundo Tipos de Organizações Civis*

\begin{tabular}{|c|c|c|c|c|c|c|c|c|c|c|c|}
\hline & \multicolumn{8}{|c|}{ Centralidade $(\%)$} & \multicolumn{3}{|c|}{ Coesão (\%) } \\
\hline & 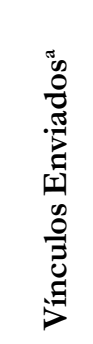 & 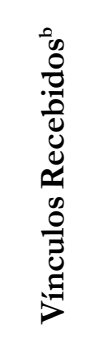 & 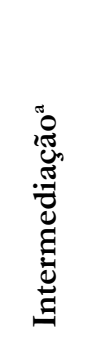 & 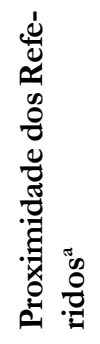 & 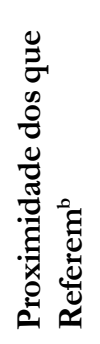 & 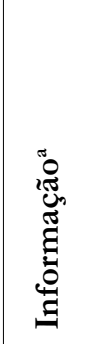 & $\begin{array}{l}\frac{\pi}{0} \\
\frac{\sigma}{0} \\
0 \\
0\end{array}$ & 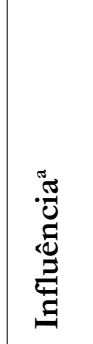 & 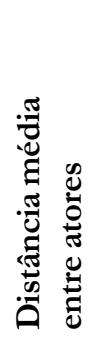 & 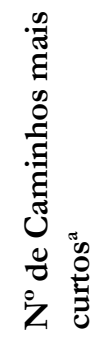 & 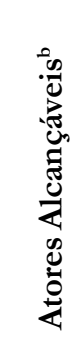 \\
\hline $\begin{array}{l}\text { Associações de } \\
\text { Bairro }\end{array}$ & $-23,4$ & $-58,5$ & $-35,6$ & $-12,9$ & $-2,7$ & $-18,6$ & $-39,8$ & $-58,7$ & $-14,4$ & $-4,7$ & $-6,2$ \\
\hline $\begin{array}{l}\text { Associações } \\
\text { Comunitárias }\end{array}$ & $-30,6$ & $-66,0$ & $-72,2$ & $-19,5$ & $-7,1$ & $-22,4$ & 49,3 & $-99,3$ & $-20,4$ & $-18,3$ & $-31,0$ \\
\hline $\begin{array}{l}\text { Entidades } \\
\text { Assistenciais }\end{array}$ & $-39,5$ & $-55,2$ & $-63,8$ & $-2,7$ & $-7,0$ & $-9,6$ & 105,6 & $-34,7$ & $-7,6$ & $-8,0$ & $-10,9$ \\
\hline Fóruns & $-29,4$ & $-47,1$ & $-67,3$ & $-10,2$ & $-0,6$ & $-16,9$ & $-11,2$ & $-75,8$ & $-14,3$ & $-11,2$ & $-19,5$ \\
\hline$\overline{\text { Demais Atores }}^{\mathrm{c}}$ & $* *$ & $* *$ & $* *$ & $* *$ & $* *$ & $* *$ & $* *$ & $* *$ & $* *$ & $* *$ & $* *$ \\
\hline
\end{tabular}

* Para o cálculo das medidas foi considerada a direção das relações.

${ }^{a}$ Médias calculadas apenas para as entidades entrevistadas $(\mathrm{n}=202)$.

${ }^{\mathrm{b}}$ Médias calculadas para toda amostra $(\mathrm{n}=829)$.

' Valor de Referência: média de médias, calculada a partir da adição das medidas para três tipos de organizações civis organizações populares, articuladoras e ONGs.

Fonte: Projeto de pesquisa "Rights, representation and the poor: comparing large developing countries - Brazil, India, Mexico".

O segundo recorte analítico foca as relações internas entre as organizações civis de cada tipo. A Tabela 2 apresenta os dados referentes ao modo como os diversos atores estabelecem relações de centralidade, intermediação, dependência etc., em suas redes internas; quer dizer, as medidas foram calculadas para sub-redes definidas por tipo de organização civil, retirando-se as conexões com os outros tipos de entidade. De maneira geral, os resultados indicam que os tipos de organizações com redes internas menos densas e mais fragmentadas coincidem com aquelas que tendem a ocupar posições periféricas na rede como um todo. Esse resultado parece apontar para uma estreita relação entre os modos de organização interna dos diferentes tipos de entidades padrões de relação, grau de coesão e hierarquização interna - e os papéis por eles desempenhados no universo das organizações civis. No caso das entidades periféricas, cabe destacar a assimetria nas relações internas às redes das associações comunitárias, bem como a eficiência no contato entre elas (muitos caminhos curtos disponíveis); no caso dos atoresponte, cabe assinalar a grande influência exercida por algumas entidades assistenciais em suas redes internas. 
Tabela 2

Centralidade e Coesão das Redes Internas de Cada Tipos de Organização Civil*

\begin{tabular}{|c|c|c|c|c|c|c|c|c|c|}
\hline & \multicolumn{6}{|c|}{ Centralidade ( $\%)$} & \multicolumn{3}{|c|}{ Coesão (\%) } \\
\hline & 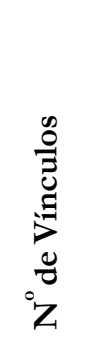 & 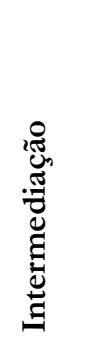 & 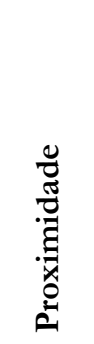 & 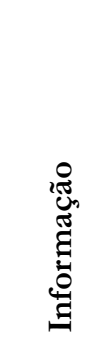 & $\begin{array}{l}\ddot{d} \\
\dot{0} \\
a\end{array}$ & 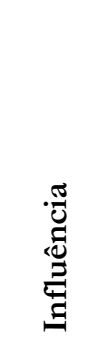 & 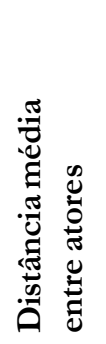 & 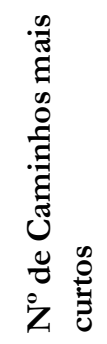 & 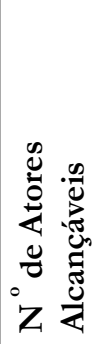 \\
\hline $\begin{array}{l}\text { Associações de } \\
\text { Bairro }(\mathrm{n}=195)\end{array}$ & $-72,2$ & $-72,5$ & $-83,3$ & $-17,1$ & 0,9 & 2,8 & 6,5 & $-20,3$ & $-64,9$ \\
\hline $\begin{array}{l}\text { Associações } \\
\text { Comunitárias }(n=64)\end{array}$ & $-67,2$ & $-96,4$ & $-54,6$ & $-30,1$ & 3,0 & $-63,5$ & $-76,1$ & $-25,7$ & $-92,8$ \\
\hline $\begin{array}{l}\text { Entidades } \\
\text { Assistenciais }(n=70)\end{array}$ & $-73,2$ & $-98,4$ & $-58,5$ & $-29,4$ & 2,5 & $-235,7$ & $-72,3$ & $-23,5$ & $-92,8$ \\
\hline Fóruns $(n=115)$ & $-73,9$ & $-96,4$ & $-74,4$ & $-44,8$ & $-0,1$ & $-44,6$ & $-59,6$ & $-25,7$ & $-89,3$ \\
\hline Demais Atores $^{c}(n=297)$ & $* *$ & $* *$ & $* *$ & $* *$ & $* *$ & $* *$ & $* *$ & $* *$ & $* *$ \\
\hline
\end{tabular}

* Para o cálculo das medidas foi considerada a direção das relações.

${ }^{\text {a }}$ Para o cálculo das médias foram consideradas todas as entidades presentes na amostra. Contudo, o tamanho das redes varia de acordo com o tipo de organização civil analisado.

${ }^{\text {b}}$ Valor de referência: média de médias, calculada a partir da adição das medidas para três tipos diferentes de organizações civis - organizações populares, articuladoras, ONGs.

Fonte: Projeto de pesquisa "Rights, representation and the poor: comparing large developing country democracies Brazil, India, Mexico".

O terceiro recorte ilumina os vínculos preferenciais das organizações civis ao atentar para as relações estabelecidas não entre as entidades na rede como um todo, nem nas redes internas, mas entre tipos diferentes de organizações. A Tabela 3 sumariza a lógica dos vínculos preferenciais na forma de um ranking simples, apresentando, em primeiro lugar, o número de vínculos novos que surgiram nas redes para cada combinação em pares por tipos de organizações civis - sem considerar os vínculos que existiam previamente nas redes internas ${ }^{14}-$; em segundo lugar, o incremento na capacidade de intermediação oriunda das relações entre dois tipos de entidades, ou seja, os ganhos de intermediaçãotambém excluindo as possibilidades de intermediação próprias à rede interna de cada tipo de organização civil; e, em terceiro lugar, o aproveita- mento real dos vínculos que potencialmente poderiam existir entre dois tipos de organizações civis (integração).

A grandes traços, observou-se que as organizações civis mais centrais são procuradas como vínculos preferenciais, especialmente por parte de entidades de base ou periféricas, as quais privilegiam claramente atores centrais na construção e na manutenção de relações. Desse modo, as entidades periféricas quase não contemplam nas suas estratégias relacionais outras organizações civis em posições semelhantes; antes, preferem vincular-se às entidades centrais. Esse é o caso, por exemplo, das associações de bairro, que mantêm relações privilegiadas com as articuladoras, ou das associações comunitárias, que mantêm preferencialmente relações com organizações populares. 
Tabela 3

Redes de Vínculos Preferenciais*

\begin{tabular}{|c|c|c|c|c|c|c|c|c|}
\hline \multirow[b]{2}{*}{$\begin{array}{l}\text { Tipologia } \\
\text { de entidades }\end{array}$} & \multirow[b]{2}{*}{$\begin{array}{l}\text { Ganhos da } \\
\text { Intersecção }\end{array}$} & \multicolumn{7}{|c|}{ Organizações com as quais se estabelecem as relações ${ }^{a}$} \\
\hline & & $\begin{array}{c}\text { Organizações } \\
\text { Populares }\end{array}$ & $\begin{array}{c}\text { Articula- } \\
\text { doras }\end{array}$ & ONGs & Fóruns & $\begin{array}{c}\text { Entidades } \\
\text { Assistenciais }\end{array}$ & $\begin{array}{c}\text { Assistência } \\
\text { de Bairro }\end{array}$ & $\begin{array}{l}\text { Assistência } \\
\text { Comunitária }\end{array}$ \\
\hline \multirow[t]{3}{*}{ Fóruns } & Vínculos novos & 4 & 3 & 2 & & 1 & 5 & 6 \\
\hline & $\begin{array}{l}\text { Ganhos de In- } \\
\text { termediação }\end{array}$ & 1 & 2 & 4 & & 3 & 5 & 6 \\
\hline & Integração & 3 & 2 & 1 & & 4 & 5 & 6 \\
\hline \multirow{3}{*}{$\begin{array}{l}\text { Entidades } \\
\text { Assistenciais }\end{array}$} & Vínculos novos & 6 & 2 & 4 & 1 & & 3 & 5 \\
\hline & $\begin{array}{l}\text { Ganhos de In- } \\
\text { termediação }\end{array}$ & 1 & 2 & 2 & 4 & & 5 & 6 \\
\hline & Integração & 2 & 3 & 1 & 5 & & 4 & 6 \\
\hline \multirow{3}{*}{$\begin{array}{l}\text { Associações } \\
\text { de Bairro }\end{array}$} & Vínculos novos & 6 & 3 & 4 & 3 & 2 & & 5 \\
\hline & $\begin{array}{l}\text { Ganhos de In- } \\
\text { termediação }\end{array}$ & 6 & 1 & 2 & 4 & 3 & & 5 \\
\hline & Integração & 6 & 1 & 3 & 4 & 2 & & 5 \\
\hline \multirow{3}{*}{$\begin{array}{l}\text { Associações } \\
\text { Comunitárias }\end{array}$} & Vínculos novos & 5 & 6 & 3 & 1 & 4 & 2 & \\
\hline & $\begin{array}{l}\text { Ganhos de In- } \\
\text { termediação }\end{array}$ & 1 & 2 & 5 & 3 & 6 & 4 & \\
\hline & Integração & 1 & 3 & 2 & 5 & 4 & 6 & \\
\hline
\end{tabular}

* Em todos os casos considerou-se a direção das relações.

${ }^{\text {a }}$ Ranking simples dos ganhos de interseção na rede estabelecida entre tipos de organizações civis.

Fonte: Projeto de pesquisa "Rights, representation and the poor: comparing large developing country democracies - Brazil, India, Mexico".

\section{Os papéis dos atores periféricos e ponte}

Embora posições periféricas e, em menor medida, intermediárias, estejam associadas a determinadas desvantagens estruturais, uma organização civil pode ocupá-las por diversos motivos, isto é, dois atores podem apresentar feições estruturais semelhantes, mas com significados muito diferentes. Os motivos são iluminados pela posição relativa de um ator na rede e não são passíveis de interpretação de forma isolada a partir de uma única medida, sendo necessária a compreensão integrada dos três ângulos analíticos expostos na seção anterior. $\mathrm{O}$ exame integrado dos resultados desses três recortes, informado pelos sociogramas das redes internas de cada tipo de organização civil, permitirá mostrar as especificidades funcionais dos atores estudados.

\section{As associacõoes de bairro}

A microterritorialidade das associações de bairro ajuda a entender sua condição periférica, pois elas conjugam a um só tempo ativismo e presença locais com posições marginais na rede como um todo. As medidas que dependem da sua atuação na construção de vínculos registram resultados superiores aos das medidas derivadas das estratégias de outros tipos de organizações civis à procura de vínculos com elas. Assim, as associações de bairro enviam mais vínculos do que recebem, apresentam relações marcadamente simétricas ${ }^{15}$ e são, na rede como um todo (inclusive entidades centrais), os atores com maior número de caminhos mais curtos e mais próximos das entidades com as quais mantêm vínculos - enquanto os atores que cultivam relações com elas são, em contraste, distantes (Tabela 1).

A análise das suas conexões internas torna mais claras as implicações do caráter territorial das associações de bairro. A julgar pelas medidas (Tabela 2), a estratégia de construir relações com seus pares é de relevância moderada, embora seja mais importante para as associações em questão do que para os fóruns e as entidades assistenciais. A especificidade, neste caso, reside no fato de elas se 
conectarem uma a uma, formando uma rede horizontal que "passo a passo" acaba por alcançar diferentes subconjuntos de atores. O Sociograma 1 mostra apenas a estrutura da rede interna das associações de bairro e permite perceber facilmente a linearidade ou o modo horizontal de extensão da rede. As associações destacadas com os quadrados, por exemplo, conseguem alcançar o extremo oposto da rede percorrendo um longo caminho. ${ }^{16}$ A lógica interna das sub-redes está pautada pela contigüidade territorial. O Sociograma $2^{17}$ mostra, por exemplo, que entidades da Zona Leste de São Paulo alcançam nicho de entidades sediadas na Zona Sul através das relações que estabelecem com entidades da Zona Norte. Um padrão relacional (fraco) animado por contigüidade territorial facilita a fragmentação, pois cada associação localizada ao longo da "linha" é importante - e boa parte delas indispensável - para a conexão com outros segmentos da rede. De fato, as relações entre associações de bairro agrupam-se em seis componentes. Por exemplo, todas as entidades de Heliópolis formam um componente à parte, sem relações com as demais entidades da zona Sul. Há, cumpre notar, um número considerável de associações de bairro isoladas (64\%) ou sem quaisquer vínculos diretos com outras associações de bairro, corroborando a correlação entre a condição central de um tipo de entidade e a construção de vínculos interpares ou com entidades do mesmo tipo. ${ }^{18}$

Mais duas feições do perfil das associações de bairro merecem destaque. $\mathrm{O}$ ativismo realizado em locais periféricos da rede vem associado a uma capacidade de intermediação razoável, bem como a uma capacidade notável de alcançar outros atores na rede (Tabela 1). Isso não constitui propriamente paradoxo; todavia, em se tratando de associações que não constroem muitos vínculos, chama a atenção sua capacidade de alcançar outras organizações e de efetuar intermediação a despeito da sua condição periférica. Tal intermediação e alcance obedecem ao padrão de vínculos preferenciais encontrado: associações de bairro privilegiam claramente as articuladoras, seguidas em patamar inferior pelas entidades assistenciais (Tabela 3); por sua vez, e malgrado essas associações não sejam vínculo preferencial de nenhum tipo de organização civil, as articuladoras mantêm certa reciproci- dade com as associações de bairro, sendo, entre os atores mais centrais, aqueles que mais cultivam relações com associações (Gurza Lavalle, Castello e Bichir, 2007). A relação privilegiada com as articuladoras - acompanhada de certa reciprocidade - é contra-intuitiva, na medida em que pareceria razoável esperar que tais vínculos preferenciais acontecessem com as organizações populares, a maioria das quais trabalha de longa data com temas urbanos lançando mão de expedientes de mobilização e pressão. Mais: as organizações populares representam o repertório de vínculos menos importante para as associações de bairro e vice-versa, e não há outro caso de relação entre dois tipos de organizações civis em que os piores vínculos possíveis sejam reciprocamente idênticos. ${ }^{19}$

Microcentralidade territorial ativa, ${ }^{20}$ com importância mínima como vinculo preferencial para outros atores, sumariza parcialmente o papel desempenhado pelas associações de bairro da sua condição periférica. Dois aspectos espantam no perfil das associações de bairro. Primeiro, sua origem local e a orientação do seu trabalho para beneficiários de camadas populares consubstanciam-se, também, nos seus vínculos preferenciais com entidades assistenciais. Entretanto, sua capacidade de intermediação, bem como a possibilidade de alcançar nichos distantes da rede decorrem das suas relações com atores altamente centrais como as articuladoras. Em outras palavras, a posição periférica das associações de bairro é compensada por um padrão relacional misto, em que comparecem, de um lado, atores-ponte - entidades assistenciais -, presumivelmente no acesso a determinados recursos privados para seus beneficiários, e, de outro, atores centrais - articuladoras - notabilizados por sua incidência na formulação de políticas públicas, provavelmente na tentativa de disputar prioridades e recursos públicos. Segundo, o fato de atores tradicionais próprios de camadas mal-aquinhoadas da população, como as associações de bairro, manterem relações privilegiadas não com as organizações populares, mas com um tipo de organização civil de recente aparição - as articuladoras, criadas fundamentalmente por ONGs -, aponta tanto para transformações relevantes ocorridas nos últimos anos no plano da ação coletiva dessas camadas como para a plasticidade da própria ação coletiva. 
Sociograma 1

Estrutura da Rede Interna das Associações de Bairro

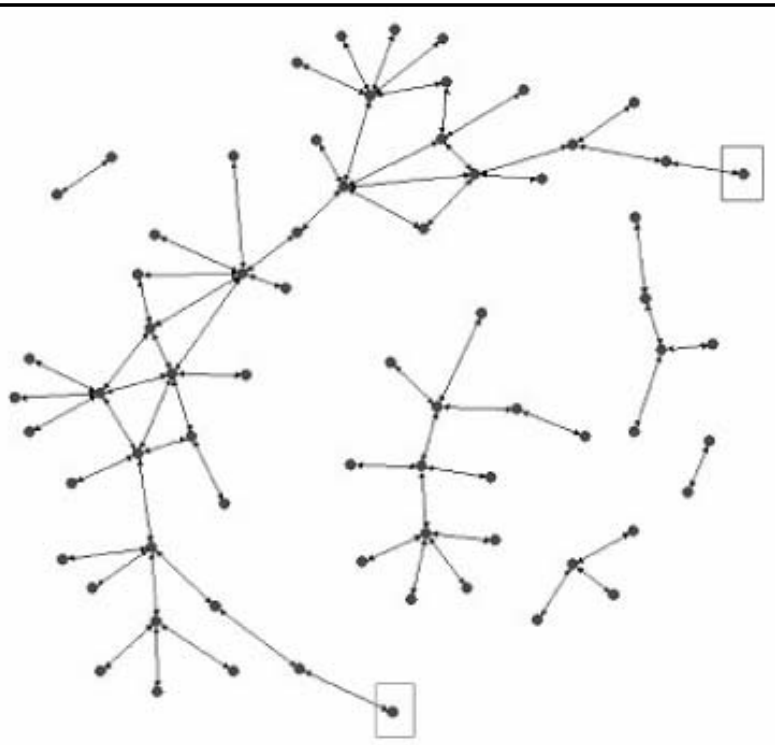

Sociograma 2

Rede Interna Associações de Bairro*

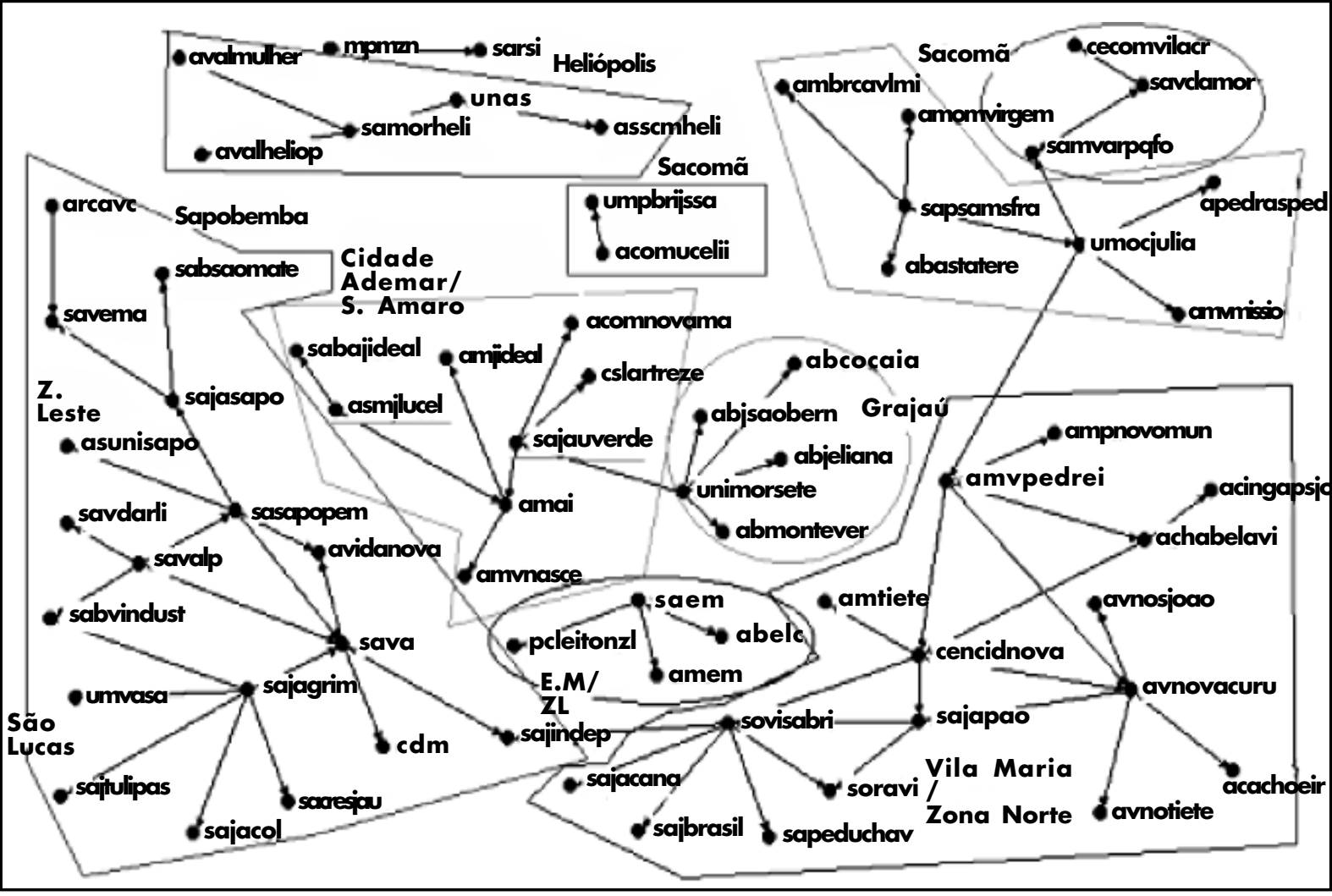

* Não estão explicitadas no sociograma as entidades que não mantêm relações com outras organizações de mesmo tipo (isoladas). Encontramos 125 associações de bairro nesta situação, ou seja, 64\% do total de associações de bairro analisadas. 


\section{As associações comunitárias}

As associações comunitárias são amostra emblemática da heterogeneidade do universo das organizações civis. De dimensões modestas, inseridas em nichos muito localizados e normalmente orientadas para a ajuda mútua, tendem a desenvolver atividades restritas e, não raro, exclusivas ao grupo de indivíduos participantes da entidade. Semelhante perfil torna-se mais nítido mediante a análise de redes, pois o traço distintivo das entidades em questão é a ausência de relações. De fato, apresentam os piores resultados em praticamente todas as medidas, excetuando a presença de "caminhos mais curtos" para alcançar outras entidades e a disposição de relações algo assimétricas (Tabela 1). Ambas as exceções acusam os efeitos do número particularmente limitado de vínculos à disposição das associações comunitárias e da existência e relações indiretas, embora limitadas, com entidades mais centrais.

As relações internas entre associações comunitárias são próximas, notavelmente assimétricas e de relevância moderada para seus protagonistas (Tabela 2). ${ }^{21}$ O Sociograma $3^{22}$ mostra que a proximidade deriva da fragmentação ou da existência de sub-redes pequenas - basicamente díades e tríades -, animadas por lógicas internas exclusivas, quer dizer, lógicas que não parecem estimular a criação de pontes com associações pares guiadas por outras preocupações. Por exemplo, os grupos de mães e as organizações civis de hip-hop apresentam relações entre si e nenhum contato com outra associação comunitária. Inclusive o nicho com o maior número de entidades - organizações representantes da polícia militar - obedece a uma lógica interna exclusiva. Neste caso, todas as relações são direcionadas a partir de um único ator. Assim, os raros vínculos estabelecidos pelas entidades em questão costumam ser pontuais e não-diversificados, tornando assimétrica a posição dos atores na sua própria rede. De modo consoante como os achados das associações de bairro, 63\% dessas associações são isoladas, ou seja, não possuem vínculos com seus pares.

O perfil exclusivista das associações comunitárias as torna a tal ponto desinteressantes para as lógicas de atuação do outros atores que, salvo a exceção da indiferença recíproca entre organizações populares e associações de bairro, as entidades em questão situam-se na última posição nas estratégias relacionais dos outros atores do universo de organizações civis estudado (Tabela 3). Por sua vez, embora as associações comunitárias privilegiem os vínculos com organizações populares, não apresentam uma hierarquia clara de relacionamento no que diz respeito às outras entidades - centrais ou não.

Associações comunitárias, de longe as mais periféricas no universo de atores estudado, são construídas por e para os integrantes de cada entidade, e isso guarda estreita conexão com o caráter exclusivo do seu padrão de relações ou com ausência delas como sua feição mais distintiva. De um lado, parecem alimentar propósitos muito restritos de expansão do seu trabalho; de outro, suas funções de ajuda mútua situam-nas em plano verdadeiramente secundário para as demais organizações. É claro que mantêm relações, mas são pontuais e animadas por afinidades exclusivas. A esse respeito cumpre lembrar como contraponto que, apesar da sua condição periférica, as associações de bairro se destacam por constituir vínculos para além do plano local e por sustentar redes relativamente extensas nesse plano.

\section{As entidades assistenciais}

Entidades assistenciais caracterizam-se, junto com os fóruns, por acusarem centralidades intermediárias, situando-se, do ponto de vista das medidas analisadas, entre as entidades periféricas e os grandes protagonistas da rede de organizações civis. Sua centralidade intermediária obedece ao exercício de uma forma de intermediação restrita, derivada das suas funções de prestação de serviços de assistência a segmentos da população ou públicos alvo definidos conforme critérios de vulnerabilidade. Elas são as entidades mais passivas do universo das organizações civis paulistanas, pois registram o pior resultado no estabelecimento de vínculos; por outro lado, apresentam posições médias quanto à proximidade com outros atores e à sua capacidade de alcance e intermediação (Tabela 1). Contudo, e não obstante sua inexpressividade na construção de relações, os vínculos por elas estabelecidos são os mais assimétricos da rede (inclusive entidades centrais), tendendo a se tornar indispensáveis para boa parte das entidades dependentes com as quais se relacionam..$^{23}$

O fato de sustentarem o repertório de relações mais assimétricas da amostra pode ser com 
Sociograma 3

Rede Interna Associações Comunitárias*
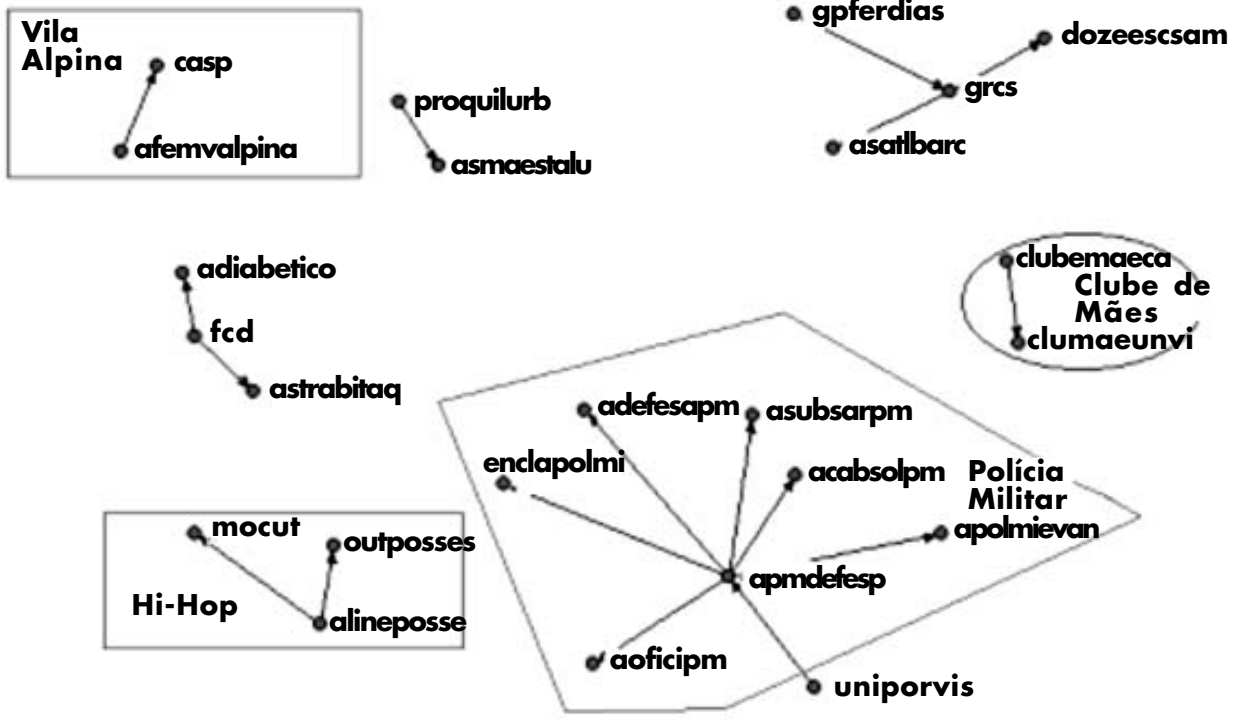

No Isolados: 125 (64\%)

* Não estão explicitadas no sociograma as entidades que não mantêm relações com outras organizações de mesmo tipo (isoladas). Encontramos quarenta associações comunitárias nesta situação, ou seja, 63\% do total de associações comunitárias analisadas.

preendido pelo seu papel como entidades-ponte entre associações mal-providas de relações com entidades densamente articuladas. De fato, as relações por elas estabelecidas tendem a ser pontuais e verticais, com ramificações limitadas. Nesse sentido, as conexões com seus pares não apenas são pouco importantes para as entidades assistenciais apenas os fóruns constroem menos vínculos entre si, e elas são as entidades que menos alcançam seus pares e com menor capacidade de intermediação na rede interna -, mas também preservam o caráter assimétrico que caracteriza suas relações com os outros tipos de organizações civis (Tabela 2). O Sociograma $4^{24}$ mostra o padrão das conexões entre entidades assistenciais. Além da fragmentação em oito componentes ou sub-redes, a estrutura de parte desses componentes revela-se assimétrica e baseada no fluxo de recursos orçamentários: a Associação Evangélica Beneficente (AEB), a Associação Brasileira de Resgate e Ação Social (Abras), o Instituto Teu Sonho Meu Sonho (Inteusonho) e a Ação Comunitária Brasil (Acaocomun), atores centrais das respectivas sub-redes, são coincidentemen te entidades assistenciais que assumem entre suas funções principais a transferência de recursos para outras entidades assistenciais. A lógica interna das sub-redes é diversa, obedecendo ora às semelhanças quanto aos públicos ou beneficiários (por exem plo, crianças), ora a alinhamentos sob fortes afinidades ideológico-institucionais, como acontece com os nichos de caráter religioso, ou ainda à proximidade territorial - como ocorre com as entidades localizadas na Zona Sul de São Paulo, no bairro de Grajaú. A despeito de ocuparem posições intermediárias, o número de entidades isoladas ou que não mantêm qualquer vínculo direto com seus pares é $(60 \%)$ semelhante ao das organizações civis periféricas.

Entidades assistenciais não constituem um vinculo privilegiado para nenhum tipo de organização central ou periférica, mas, de modo paralelo aos fóruns, são procuradas por todas as organizações civis - confirmando sua posição de centralidade intermediária - e, em particular, pelas associações de bairro (Tabela 3). Os vínculos preferenciais cultivados pelas entidades em questão respeitam o 
padrão mais geral, ou seja, privilegiam as organizações civis mais centrais; e entre associações periféricas, optam pelas associações de bairro em vez das comunitárias.

As medidas de centralidade conferem às entidades assistenciais lugar intermediário dentro de um ranking relacional, mas o exame integrado das mesmas revela um perfil funcional em que essas entidades desempenham o papel de atores-ponte entre conjuntos de atores posicional e hierarquicamente separados na rede. É pertinente frisar que a obtenção de resultados próximos da mediana daí a denominação de entidade de centralidade intermediária - não guarda qualquer relação necessária com o exercício de funções de intermediação. A primeira é um resultado aritmético, enquanto as segundas são produto de uma interpretação sociológica do conjunto integrado das medidas visando a caracterizar o modo de operação do tipo de organização sob exame. Assim, o fato de as entidades assistenciais operarem como atores-ponte remete ao seu perfil como mediadoras entre captação e canalização de recursos destinados à assistência e à benemerência, conectando organizações financiadoras, sustentadoras ou doadoras, bem aparelhadas relacionalmente, com atores periféricos, como as associações de bairro, próximas dos públicos visados como alvo da assistência. Trata-se de um tipo e mediação restrito e vertical, o que explica seu desinteresse na construção ativa de vínculos ou de redes (networking) com outros tipos de organizações civis e entre elas próprias. Tal caracterização, cumpre salientar, sugere certo aprimoramento para as leituras sobre o processo de "onguização" das entidades assistenciais, pois, a despeito de tal diagnóstico, os padrões encontrados semelham a uma espécie de impressão digital relacional que identifica e distingue claramente ONGs de entidades assistenciais. Se a eventual mudança estiver a acontecer, parece conveniente procurá-la no plano discursivo e simbólico.

Sociograma 4

Rede Interna Entidades Assistenciais*

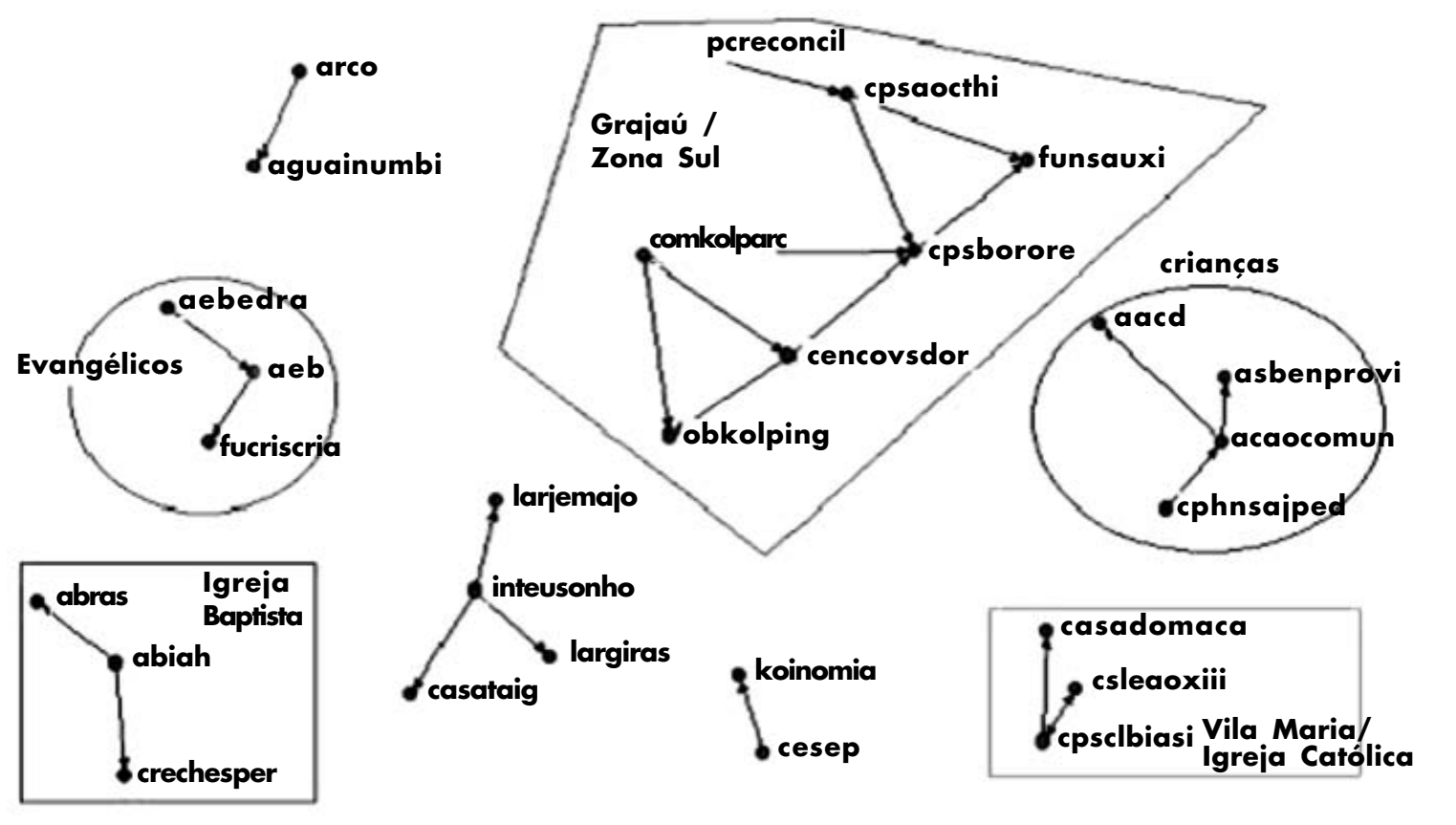

* Não estão explicitadas no sociograma as entidades que não mantêm relações com outras organizações de mesmo tipo (isoladas). Encontramos 42 entidades assistenciais nesta situação, ou seja, 60\% do total de entidades assistenciais analisadas. 


\section{Os Fóruns}

Os resultados dos fóruns são plenamente condizentes com seu papel de atores-ponte, e permitem especificar seu perfil relacional como instâncias de encontro, definição e orientação programática de atores com vocações temáticas e preocupações afins. Seu padrão de centralidade intermediária apresenta um papel ativo na construção de vínculos que, no entanto, é desbalanceado devido à enorme quantidade de vínculos recebidos ${ }^{25}$ Fóruns recebem consideravelmente mais do que enviam vínculos, encontram-se próximos das entidades que os procuram, mas distantes daquelas com as quais eles constroem relações, e possuem baixa capacidade de intermediação (Tabela 1). ${ }^{26}$ Quando observados em comparação às entidades assistenciais, surge contraste interessante, pois os fóruns sustentam relações bem menos assimétricas - a despeito de ambos os tipos de organizações civis compartilharem posições de centralidade intermediária.

Justamente por serem instâncias temáticas de encontro que abrigam outros tipos de organizações civis, os fóruns distinguem-se pela acessibilidade e não apresentam inclinação a estabelecer vínculos entre si, a não ser no caso raro de sobreposições nos temas trabalhados. Nesse sentido, o padrão de conexões internas do tipo de ator em questão é o mais desconexo e menos centralizado de todas as redes entre pares no universo de organizações civis paulistanas aqui analisado (Tabela 2). O Sociograma $5^{27}$ ilustra nitidamente a magnitude da desconexão: além de tenderem a ser pontuais, ordenando a rede em cinco componentes - três díades, uma tríade e um componente maior, as relações internas dos fóruns são raras, visto que 83\% são isolados ou não possuem qualquer relação direta com outros fóruns. Trata-se, de longe, do tipo de organização civil que menos mantém vínculos entre si. O sociograma também permite apreciar o caso raro de sobreposições temáticas parciais que animam a construção de pequenas sub-redes: o Fórum "ONGs Aids", por exemplo, mantém re- lação com o Fórum de Patologias; o Fórum do Idoso, por sua vez, sustenta vínculos com os de Assistência Social e de Saúde.

Os fóruns constituem vínculo cultivado pela maior parte das organizações estudadas, embora nunca em posição privilegiada e, é claro, nunca antecedendo as entidades mais centrais - organizações populares, articuladoras e ONGs. Embora a afirmação recíproca também seja verdadeira - fóruns também privilegiam vínculos com organizações civis centrais -, um olhar cuidadoso sugere maior afinidade com entidades centrais de perfil temático, ou seja, com articuladoras e ONGs (Tabela 3). Por sua vez, organizações populares e entidades assistenciais encontram-se em patamar inferior com importância semelhante para os fóruns, e associações de bairro e comunitárias são irrelevantes nos termos relativos do ranking utilizado.

Fóruns abrigam inquietações e problemas das organizações civis, e brindam um espaço para elaboração de consensos a seu respeito. Entretanto, não constituem o canal para transmissão ou difusão de tais consensos, pois, uma vez adensados, eles são divulgados e, na medida do possível, implementados e/ou disputados na prática pelas organizações civis que participam do respectivo fórum. Seu papel de instâncias de adensamento dos discursos, programas de ação e interações de outras organizações civis afastam-nos de estratégias ativas na construção de relações, mas na medida em que são freqüentados em igual medida por organizações civis centrais e periféricas representam uma instância de aproximação entre entidades desiguais em termos da sua capacidade de ação. Assim, o papel de ator-ponte vem marcado pela acessibilidade, diferentemente das entidades assistenciais, que também permitem o contato entre conjuntos hierarquicamente afastados de organizações civis, mas de modo restrito e vertical. Em ambos os casos, todavia, parece plausível afirmar a coincidência entre funções de intermediação e a presença de padrões de relacionamento heterófilos ou preferencialmente orientados para outros tipos de atores. 
Sociograma 5

Rede Interna dos Fóruns
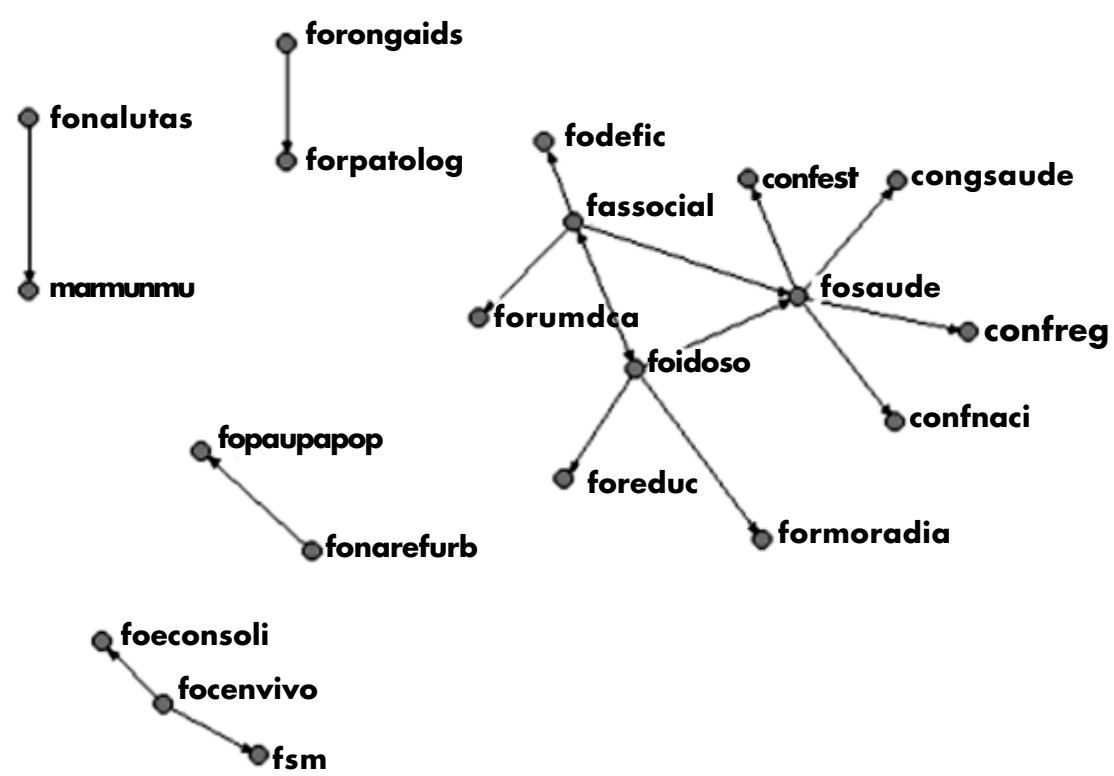

* Não estão explicitadas no sociograma as entidades que não mantêm relações com outras organizações de mesmo tipo. Encontramos 95 fóruns nesta situação, ou seja, $83 \%$ do total de fóruns analisados.

\section{Comentário Final}

Um dos deslocamentos mais perceptíveis da literatura recente é afirmar a idéia da heterogeneidade da sociedade civil. Contudo, cabe ao esforço da pesquisa sistemática desvendar os modos em que tal heterogeneidade se organiza. Se o universo das organizações civis não se ordena nem seus atores comportam como prescrito pela teoria guiados por uma lógica unificadora e por compromissos normativos passíveis de universalização -, há sem dúvida terreno fértil para a elaboração de distinções analíticas positivas e empiricamente alicerçadas, capazes de contribuir para a compreensão das lógicas que animam o modus operandi das organizações civis. Aqui, o funcionamento do universo das organizações civis, particularmente dos seus atores com menor protagonismo, foi reconstruído relacionalmente a partir de três recortes analíticos já comentados. Afortunadamente, monismos metodológicos não mais parecem em voga hoje e, por certo, a análise de redes é uma estratégia de abordagem entre outras possíveis para lidar com atores coletivos. No entanto, a magnitude numérica, a diversidade e a pulverização do universo das organizações civis tornam-na peculiarmente adequada para contornar as limitações de perspectivas centradas no ator como instância privilegiada de análise e como fonte de (auto)produção de conhecimento.

No universo das organizações civis paulistanas operam hierarquias acentuadas quanto às capacidades de ação e escolha dos diferentes tipos de atores, acompanhadas de clivagens de especialização ou diferenciação funcional. Os dados alinham claramente entidades marcadas por sua condição periférica - associações comunitárias e de bairro e entidades com uma condição de centralidade intermediária - assistenciais e fóruns. Não cabe aqui repetir as sínteses analíticas formuladas, mas é pertinente frisar que as posições ocupadas pelas organizações civis nessas divisões impõem constrangimentos, mas não constituem uma condenação à 
impotência. Antes, é possível desenvolver estratégias compensatórias bem-sucedidas, visando a franquear o acesso das entidades periféricas a recursos materiais e simbólicos que fluem pelos locais mais centrais da rede. A análise revelou o papel que entidades assistenciais e fóruns desempenham como atores-ponte - intermediando diferentes tipos e recursos, materiais no primeiro caso, simbólicos e políticos no segundo -, mas também mostrou a presença de conexões diretas ou não-mediadas entre nichos periféricos de atores e entidades centrais, como é o caso dos vínculos preferenciais entre associações de bairro e articuladoras.

A existência de organizações civis dedicadas a propósitos distintos e empenhadas na realização de atividades diferentes remete ao plano do pluralismo societário ou da heterogeneidade da ação coletiva, mas a presença de funções complementares implica algo mais: processos intencionais de diferenciação funcional ou divisão do trabalho, cuja cristalização poderia atestar o grau de complexidade e a capacidade de atuação de atores situados dentro do universo das organizações civis. Entrementes, não há conhecimento acumulado que permita examinar sistematicamente as implicações mais amplas dos padrões relacionais documentados mediante comparações intertemporais ou com outros universos de organizações civis. Seria desejável que essa lacuna fosse sanada, permitindo a re-especificação e, eventualmente, a refutação desses padrões graças ao acúmulo de evidências oriundas de outros contextos no Brasil e no exterior.

No plano da teoria de redes, os achados das entidades periféricas e intermediárias confirmam que a centralidade de um ator pode obedecer a inserções passivas ou ativas na rede. A diferença entre centralidades passivas e ativas, observada também no caso das organizações protagonistas (Gurza Lavalle, Castello e Bichir, 2007), parece associada, no primeiro caso, a prestigio e assimetria relacional, isto é, a desigualdades acentuadas de recursos; já no segundo, a associação parece ser com relações homofilicas - entre entidades do mesmo tipo - e com outros atores munidos de recursos relativamente semelhantes. Além disso, o exame dos atores-ponte sugere que a especialização funcional desempenhando papéis de bridging está associada a padrões relacionais heterófilos. Em princípio, se esses achados se revelarem consistentes, seria possível avançar especificando conceitualmente os signi- ficados de modalidades de centralidade quando as redes são compostas por organizações civis, detectando coincidências e eventuais especificidades em face de formulações mais abstratas, características da teoria de redes.

\section{Notas}

1 Para a afirmação idéia de heterogeneidade da sociedade civil na literatura, ver Olvera (2003), Encarnación (2006), Dagnino, Olvera e Panfichi (2006).

2 Para balanços críticos no Brasil e na América Latina, ver Dagnino, Olvera e Panfichi (2006) e Gurza Lavalle (2003); para balanços mais gerais, ver a coletânea de trabalhos organizada por Alexander (1998) e Encarnación (2006).

3 Trata-se de autores do debate teórico internacional que, nos anos de 1990, apostaram no fortalecimento da sociedade civil como "nódulo normativo de um projeto radical democrático", como "um desiderato político-emancipatório" (Costa, 1997, p. 9). Os autores são bem conhecidos pela sua obra e influência: Andrew Arato, Jean Cohen, Charles Taylor, John Keane, Michel Walzer.

4 Para distinções analíticas, ver "projeto", em Dagnino, Olvera e Panfichi (2006); "trajetórias”, em Delamaza e Ochsenius (2006), Feltran (2005); “desenho institucional", em Fung (2004) e Fung e Wright (2003); accountability, em Fox (2006), Alnoor e Weisband (2007); "representação presuntiva" e "formulações equivalentes”, em Mansbridge (2003), Castiglione e Warren (2005), Peruzzotti (2005), Urbinati (2000), Gurza Lavalle, Houtzager e Castello (2006a, 2006b); “ecologia associativa”, em Warren (2004); "redes de atores", em Alvarez, Dagnino e Escobar (1998), no sentido metafórico e pioneiro apontado no texto, em Diani e McAdam (2003).

5 No trabalho de campo foram entrevistadas 229 organizações civis, mas devido a critérios metodológicos foram contempladas apenas 202 na análise de redes.

6 A análise de redes apenas pressupõe que o mundo é relacional, mas a desigualdade de relações disponíveis na rede para seus diferentes atores é uma característica empírica da rede. Por outro lado, a probabilidade de concentração de poder aumenta conformem o tamanho da rede - conforme Hanneman (2001) -, mas o grau de desigualdade e as 
posições relativas dos atores analisados também são de índole empírica.

7 A metáfora da "ponte" salienta a função de conexão entre dois territórios - por extensão, realidades ou mundos - e nesse sentido se omite de especificar os benefícios dos atores, enquanto idéias brokerage e gate-keeping enfatizam os custos da intermediação a serem pagos por quem dela precisa. Conforme será mostrado na análise das entidades assistências e dos fóruns, as funções de conexão obedecem a lógicas mais diversas do que aquelas próprias de uma economia da intermediação. Para as definições de broker ou gatekeeper, ver Scott (1992, p. 90) e Wasserman e Faust (1994, pp. 188-191).

8 Organizações populares são atores específicos voltados para a mobilização coletiva a propósito de demandas populares. Articuladoras são atores fundados por outras organizações civis para representar seus interesses e coordenar a ação dos seus fundadores e membros, isto é, trabalham para entidades e não para segmentos específicos da população. ONGs são entidades de advocacy, dedicadas a reivindicar demandas de terceiros e a tematizar publicamente problemas visando à construção de consensos sociais. Para uma exposição detalhada da tipologia expandida, ver Gurza Lavalle, Castello e Bichir (2008).

9 Para uma discussão conceitual a respeito das medidas de centralidade e coesão utilizadas usualmente nas análises de redes sociais, bem como das vantagens a elas associadas, ver Hanneman (2001).

10 Optou-se por diferenciar a origem e o destino dos vínculos entre as organizações. Entretanto, por motivos técnicos, as relações presentes na rede foram consideradas de modo simétrico no caso de algumas medidas.

11 Os resultados apresentados neste artigo fazem parte do projeto "Rights, Representation and the Poor: Comparing Large Developing Country Democracies - Brazil, India and Mexico". As informações metodológicas, bem como o questionário (Houtzager, Gurza Lavalle e Acharya 2003), encontram-se disponíveis para consulta na página do projeto, site http://www.ids.ac.uk/gdr/cfs/research/Collective $\% 20$ Actors.html.

12 Todas as medidas a serem apresentadas foram estimadas mediante a aplicação de diferentes ponderadores (normalização) para controlar os efeitos decorrentes do peso dos distintos tipos de organização civil na amostra.

13 Trata-se de uma média de médias; os resultados dos três tipos de entidades centrais foram calculados separadamente.

14 Para tanto, foram considerados apenas os ganhos obtidos em cada um dos cruzamentos entre dois tipos de organizações civis, cancelando os resultados oriundos das redes internas. Em outras palavras, consideram-se apenas os saldos da interseção entre duas redes.

15 Apresentam os resultados mais baixos na medida "poder", que afere assimetria relacional.

16 Não é fortuito o fato de possuírem a maior distância geodésica (ver Tabela 1).

17 Atores: Abastatere - Associação do Bairro Amigos de Santa Terezinha; Abcocaia - Associação do Bairro Cocaia; Abelc - União de Projetos Assistenciais à Comunidade; Abjeliana - Associação do Bairro Jardim Eliana; Abjsaobern - Associação do Bairro Jardim São Bernardo; Abmontever - Associação do Bairro Monte Verde; Acachoeir - Associação Cachoeirinha; Achabelavi - Associação Chácara Bela Vista; Acingapsjo - Associação Cingapura Parque São João; Acomnovama - Associação Comunitária Nova Marilda; Acomucelii - Associação de Construção por Mutirão Jd. Celeste II; Amai - Associação dos Moradores de Vila Arco Íris; AMBRCAVLMI - Associação de Moradores do Bairro Rita Cavernaqui e Vl. Missionária; Amem - Associação dos Moradores de Ermilíno Matarazzo; Amjideal - Associação de Moradores do Jardim Ideal; Amomvirgem - Associação de Moradores de Mata Virgem; Ampnovomun - Associação de Moradores de Parque Novo Mundo; Amtiete - Associação de Moradores do Tietê; Amvmissio - Associação de Moradores da Vila Missionária; Amvnasce - Associação de Moradores de Vila Nascente; Amvpedrei - Associação dos Moradores da Vila Pedreira; Apedrasped - Associação Pedra sobre Pedra; ARCAVC - Associação Recreativa Comunitária Amigos de Vila Carmem; ASMJLUCEL - Associação dos Moradores do Jardim Lucélia; ASSCMHELI Associação Central dos Moradores de Heliópolis; Asunisapo - Associação Unidas Beneficente de Sapopemba e Vilas Adjacentes; Avalheliop - Associação pela Valorização de Heliópolis; Avalmulher Associação de Valores da Mulher; Avidanova - Associação Vida Nova; Avnosjoao - Associação Vila 
Nova São João; Avnotiete - Associação Vila Nova Tiête; Avnovacuru - Associação Vila Nova Curuça; CDM - Vila Darli; CECOMVILACR - Centro Comunitário da Vila Cristália; Cencidnova - Centro Social Cidade Nova; CSLARTREZE - Centro Social Largo Treze; MPMZN - Movimento Popular de Moradia Zona Norte; PCLEITONZL - Pequeno Cleiton da Zona Leste; Sabajideal - Sociedade Amigos do Bairro Jardim Ideal; Sabsaomate - Sociedades Amigos do Bairro de São Mateus; Sabvindust - Sociedade Amigos de Bairro Vila Industrial; Sacresjau - Sociedade Amigos Conj. Residencial Jaú; Saem - Sociedade Amigos de Ermilíno Matarazzo; Sajacana - Sociedade Amigos de Jaçana; Sajacol Sociedade Amigos do Jardim Colorado; Sajagrim Sociedade Amigos do Jardim Grimaldi; Sajapao Sociedade Amigos do Jardim Japão; Sajasapo Sociedade Amigos do Jardim Sapopemba; Sajauverde - Sociedade Amigos do Jd. Aury Verde e Adjacências; Sajbrasil - Sociedade Amigos do Jardim Brasil; Sajindep - Sociedade Amigos do Jardim Independência; Sajtulipas - Sociedade Amigos Jardim das Tulipas; Samorheli - Sociedade Amigos Moradores de Heliópolis; SAMVARPQFO - Sociedade Amigos da Vila Arapuá e Parque Fongar; Sapeduchav - Sociedade Amigos do Parque Edu Chaves; Sapsamsfra - Sociedade Amigos do Parque Santa Amélia e Balneário São Francisco; SarsiSociedade Amigos de Bairro da Região de Santa Inês; Sasapopem - Sociedade Amigos de Sapopemba; Sava - Sociedade Amigos de Vila Alpina; Savalp - Sociedade Amigos de Vila Alpina; Savclamor Sociedade Amigos de Vila Cristália, Vila Lalá e Jd. Morgado ; Savdarli - Sociedade Amigos de Vila Darli; Savema - Sociedade Amigos de Vila Ema; Soravi-Sociedade Amigos de Vila Medeiros; Sovisabri - Sociedade Vila Sabrina; Umocjulia - União dos Moradores da Cidade Júlia; UMPBRIJSSA União dos Moradores do Parque Bristol e Jardim São Savério; Umvasa - União de Moradores de Antonio dos Santos e Adjacentes; Unas - União de Núcleos, Associações e Sociedades dos Moradores de Heliópolis; Unimorsete - União dos Moradores da Comunidade de Sete de Setembro.

A rede interna de ONGs apresenta 33\% de isoladas na amostra aqui analisada; as organizações populares, 47\%, e articuladoras, 54\% (Gurza Lavalle, Castello e Bichir, 2007).

19 Para as três formas de aferir os ganhos da interseção, organizações populares e associações de bairro apa- recem reciprocamente em $6^{\circ}$ lugar. Os resultados das organizações populares podem ser consultados em Gurza Lavalle, Castello e Bichir (2007).

20 Por oposição a centralidades passivas derivadas da recepção de vínculos.

21 Próximas conforme as medidas "proximidade" e "caminhos mais curtos", e assimétricas conforme a medida "poder" (Tabela 2).

22 Atores: ACABSOLPM - Associação de Cabos e Soldados da Polícia Militar; ADEFESAPM - Associação de Defesa do Policial Militar; Adiabetico Associação dos Diabéticos; Afemvalpina - Associação Feminina de Vila Alpina; Alineposse - Aliança Negra Posse; AOFICIPM - Associação de Oficiais da Polícia Militar; APMDEFESP - Associação da Polícia Militar dos Deficientes do Estado de São Paulo; Apolmievan - Associação de Policiais Militares Evangélicos; ASATLBARC - Associação Atlética Barcelona; Asmaestalu - Associação de Mães de Santa Luzia; Astrabitaq - Associação dos Trabalhadores de Itaquera; ASUBSARPM - Associação de Subtenentes e Sargentos da Polícia Militar; Casp Centro de Ação Social de Vila Alpina; Clubemaeca Clube de Mães Coração do Amor; Clumaeunvi Clube das Mães Unidas para a Vitória; DOZEESCSAM - 12 Escolas de Samba do Grupo Especial; Enclapolmi - Entidades de classe da Polícia Militar; FCD - Fraternidade Cristã de Doentes e Deficientes; GPFERDIAS - Grupo de Senhoras Unidas Fernão Dias; GRCS - Grupo Recreativo Cultural e Social Escola de Samba Acadêmicos do Tucuruvi; Mocut - Movimento Cultural da Cidade Tiradentes; Outposses - Outras Posses (organizações de Hip Hop); Proquilurb - Projeto Quilombos Urbanos; Uniporvis - União dos Portadores de Deficiência Visual do Estado de São Paulo.

23 Conforme o resultado da medida "poder" na Tabela 1 .

24 Atores: AACD - Ação Comunitária do Brasil; Abiah - Associação Batista de Incentivo e Apoio ao Homem; Abras - Associação Brasileira de Resgate e Ação Social; Acaocomun - Ação Comunitária; AEB - Associação Evangelista Beneficiente; Aebedra Associação Evangélica Beneficiente e Educacional Diácono Renato Araújo; Aguainumbi - Associação Guainumbi; Arco - Associação Beneficiente Arco; Asbenprovi-Associação Beneficiente Provisão; Casadomaca - Casa Dom Macária; Casataig Casa Taiguara; CENCOVSDOR - Centro de Con- 
vivência Santa Dorotéia; Cesep - Centro Educacional São Paulo Apóstolo; Comkolparc - Comunidade Kolping Arco-Íris; CPHNSAJPED - Centro de Promoção Humana Nossa Senhora Aparecida do Jd. Pedreira; CPSAOCTHI - Centro de Promoção Social São Caetano Thiene; CPSBORORE Centro de Promoção Social Bororê; CPSCLBIASI - Centro de Promoção Social Cônego Luis Biasi; Crechesper - Creche Esperança; CSLEAOXIII Centro Social Leão XIII; Fucriscria - Fundo Cristão para Criança; Funsauxi - Fundação Nossa Senhora Auxiliadora; Inteusonho - Instituto Teu Sonho Meu Sonho; Koinomia; Largiras - Lar Girassol; Larjemajo - Lar Jesus Maria José; OBKOLPING Obra Kolping do Brasil; PCRECONCIL - Programa Comunitário Reconciliação.

25 Ver as medidas "vínculos recebidos" e, sobretudo, "influência".

26 Proximidade em relação aos atores que citam os fóruns, mas não só. Note-se o grande número de "caminhos mais curtos" e "balanço favorável" entre vínculos enviados e recebidos (influência) (Tabela 1).

27 Atores: Confest - Conferências Estaduais; Confnaci - Conferências Nacionais; Confreg-Conferências Regionais; Congsaude - Congresso da Saúde; Fassocial - Fórum de Assistência Social; Focenvivo - Fórum Centro Vivo; Fodefic - Fórum de Deficientes; Foeconsoli - Fórum da Economia Solidária; Foidoso - Fórum do Idoso; Fonalutas Fórum Nacional de Lutas; Fonarefurb - Fórum Nacional de Reforma Urbana; Fopaupapop - Fórum Paulista de Participação Popular; Foreduc Fórum de Educação; Formoradia - Fórum de Moradia; Forongaids - Fórum Ongs Aids; Forpatolog - Fórum de Patologia; Forumdca - Fórum dos Direitos da Criança e do Adolescente; Fosaude - Fórum de Saúde; FSM - Fórum Social Mundial; Marmunmu - Marcha Mundial de Mulheres

\section{BIBLIOGRAFIA}

ALNOOR, Ebrahim \& WEISBAND, Edward (cords.). (2007), Global accountabilities: participation, pluralism, and public ethics. Cambridge, Cambridge University Press,

ALVAREZ, Sonia E.; DAGNINO, Evelina \& ESCOBAR A. (orgs.). (1998), Culture of politics, politics of culture: re-visioning Latin American social movements. Boulder, CO, Westview.
ALEXANDER, J. (1998), Real civil societies: dilemmas of institutionalization. Londres/Thousand Oaks, Sage.

ARATO, Andrew. ([1994] 1995), "Ascensão, declínio e reconstrução do conceito de sociedade civil: orientações para novas pesquisas". Revista Brasileira de Ciências Sociais, 27: 18-27, fev.

AVRITZER, Leonardo. (1997), "Um desenho institucional para o novo associativismo". Lua Nova, 39: 149-174.

. (org). (2004), O associativismo em São Paulo. São Paulo, Editora da Unesp.

AVRITZER, Leornardo; RECAMÁN, Mariso \& VENTURI, Gustavo. (2004), “O associativismo na cidade de São Paulo", in Leonardo Avritzer (org.), O associativismo em São Paulo, São Paulo, Editora da Unesp.

BEBBINGTON, A. (2002), "Reflexões sobre a relação norte-sul na construção de conhecimentos sobre as ONGs na América Latina", in $\mathrm{S}$ Haddad (org.), ONG e universidades: desafios para a cooperação na América Latina, São Paulo, Editora Fundação Peirópolis.

BOSCHI, Renato Raul. (1987), $A$ arte da associação: política de base e democracia no Brasil. Rio de Janeiro, Vértice/Iuperj.

CARVALHO, Maria do Carmo Brant. (1998), "Sociedade civil, Estado e terceiro setor". São Paulo em Perspectiva, 12 (4): 83-91, out./dez.

CASTIGLIONE, Dario \& WARREN, Mark E. (2005), "Rethinking representation: seven theoretical issues". Prepared for delivery at the Midwest Political Science Association Annual Conference Chicago, IL, April 6-10.

COELHO, Simone de Castro Tavares. (2000), Terceiro setor: um estudo comparado entre Brasil e Estados Unidos. São Paulo, Senac.

COHEN, Jean \& ARATO, Andrew. (1992), Sociedad civil y teoría politica civil. México, Fondo de Cultura Económica.

COSTA, Sérgio. (1997), "Movimentos sociais, democratização e a construção de esferas públicas locais". Revista Brasileira de Ciências Sociais, 35: 121-134.

COSTA, Sérgio. (1997), "Categoria analítica ou passe-partout político-normativo: notas bibliográficas sobre o conceito de sociedade civil". Revista Brasileira de Informação Bibliográfica em Ciências Sociais - BIB, 43: 3-25.

DAGNINO, Evelina. (2002), "Sociedade civil e espaços públicos no Brasil”, in Evelina Dag- 
nino (org.), Sociedade civile espaçospúblicos no Brasil. São Paulo/Campinas, Paz e Terra/Fundação Ford/Instituto de Filosofia e Ciências Humanas da Unicamp.

DAGNINO, Evelina; OLVERA, Alberto \& PANFICHI, Aldo. (2006), A disputa pela construção democrática na América Latina. São Paulo, Paz e Terra.

DELAMAZA, G. \& OCHSENIUS, Carlos. (2006), "Trajetórias, redes e poder: sociedade civil e política na transição democrática chilena", in E. Dagnino, A. Olvera e A. Panfichi (orgs.), A disputa pela construção democrática na América Latina, São Paulo/Campinas, Paz e Terra/ Editora da Unicamp.

DIANI, G \& McADAM, D. (2003), Social movements and networks: relational approaches to collective action. Oxford, Oxford University Press.

DOIMO, Ana Maria. (1995), A vez e voz do popular: movimentos sociais e participação politica no Brasil pós-70. São Paulo/Rio de Janeiro, Anpocs/ Relume Dumará.

. (2004), "Pluralidade religiosa à brasileira, associativismo e movimentos sociais em São Paulo", in Leonardo Avritzer (org.), O associativismo em São Paulo, São Paulo, Editora da Unesp.

EMIRBAYER, Mustafa. (1997), "Manifesto for a relational sociology". American Journal of Socio$\log y, 103$ (2): 281-317.

ENCARNACIÓN, Omar G. (2006). "Civil society reconsidered". Comparative Politics, 38 (3): 357-376, abr.

FELTRAN, Gabriel. (2005), Desvelar a politica na periferia: história de movimentos sociais em São Paulo. São Paulo, Humanitas/Fapesp.

FERNANDES, R. (2002). Privado, porém público: o terceiro setor na América Latina. Rio de Janeiro. Relumé Dumará/Civicus.

FLEURY, Sônia. (1994), Estado sem cidadãos: seguridade social na América Latina. Rio de Janeiro, Fiocrusz.

FOX, Jonathan. (2006), "Sociedad civil y políticas de rendición de cuentas". Perfiles Latinoamericanos, 27: 33-68, FLACSO, México.

FUNG, Archon. (2004). Empowered participation: reinventing urban democracy. Princeton, Princeton University Press.

FUNG, Archon \& WRIGHT, Eric Olin. (2003), "Thinking about empowered participatory governance", in (eds.), Deepening democracy: institutional innovation in empowered participatory governance. Londres, Verso.

GURZA LAVALLE, Adrián. (2003), "Sem pena nem gloria: o debate da sociedade civil nos anos 1990". Novos Estudos, 66: 91-110, jul.

GURZA LAVALLE, Adrián; CASTELLO, Graziela \& BICHIR, Renata M. (2004). "Quando novos atores saem de cena: continuidades e mudanças na centralidade dos movimentos sociais". Cultura e Politica, 10 (2): 35-53, Santa Catarina, UFSC.

. (2007), "Protagonistas na sociedade civil: redes e centralidades de organizações civis em São Paulo". Dados, 50 (3): 465-498.

. (2008), "The backstage of civil society: protagonisms, networks, and affinities between civil organizations in São Paulo". Brighton, IDS Working Paper 229.

GURZA LAVALLE, Adrián; HOUTZAGER, Peter \& CASTELLO, Graziela. (2006a), "Democracia, pluralização da representação e sociedade civil". Lua Nova: Revista de Cultura e Política, 67: 49-103.

. (2006b), "Representação política e organizações civis: novas instâncias de mediação e os desafios da legitimidade". Revista Brasileira de Ciências Sociais, 21 (60): 43-66.

GURZA LAVALLE, Adrián; ARCHAYA, A \& HOUTZAGER, P. (2005), "Beyond comparative anecdotalism: lesson on civil society and participation from São Paulo, Brazil", World Development, 33 (6): 40-48 [special edition: "Exploring the politics of poverty reduction: how are the poor represented"].

HANNEMAN, Robert A. (2001), "Introduction to social network methods". Disponível no site <http://faculty.ucr.edu/ hanneman/ SOC157/NETTEXT.PDF>.

HOUTZAGER, P.; GURZA LAVALLE, A. \& ACHARYA, A. (2003), "Who participates? Civil society and the new democratic politics in São Paulo, Brazil”. IDS Working Paper 210, Brighton: Institute of Development Studies.

LANDIM, Leilah. (1998), “"Experiência militante’: histórias das assim chamadas ONGs", in (org.), Ações em sociedade: militâncias, caridade, assistência, etc. Rio de Janeiro, Iser/NAU. . (2002), "Múltiplas identidads das ONG's", in Sérgio Haddad (org.), ONGs e 
universidades: desafios para cooperação na América Latina. São Paulo, Abong.

MANSBRIDGE, Jane. (2003), "Rethinking representation". American Political Science Review, 97: 515-528, Cambridge University Press.

OLVERA, Alberto. (2003), Sociedad civil, esfera públic y democratización en América Latina: México. México, DF, Universidad Veracruzana/Fondo de Cultura Económica.

OOMMEN, T. K. (2004), Nation, civil society and social movements: essays in political sociology. New Delhi/ Thousand Oaks/Londres, Sage Publications.

PAZ, Rosângela. (2005), "Organizações não-governamentais: um debate sobre a identidade política das associadas à Abong”. Cadernos Abong, 33 , jun.

PERISSINOTTO, Renato M. (2004), "Política e sociedade: por uma volta à sociologia política". Politica \& Sociedade - Revista de Sociologia e Política, 1 (5): 201-230, out., Universidade Federal de Santa Catarina.

PERUZZOTTI, Enrique. (2005), “Two aproaches to representation". Trabajo preparado para el Taller sobre Representación Política em América Latina, Funndación Pent, Bueno Aires.

REIS, G \& FREIRE, J. (2002), "Participação e arenas públicas: um quadro analítico para pensar os conselhos setoriais municipais e os fóruns de desenvolvimento local". 'Trabalho apresentado no XXVI Encontro Nacional da Anpocs.

SCOTT, J. (1992), Social network analysis. Newbury Park, California, Sage Publications.

SINGER, Paul \& BRANT, Vinicius Calderia (orgs.). (1980), São Paulo: o povo em movimento. São Paulo, Vozes/Cebrap.

TANDON, Rajesh \& MOHANTY, Ranjita. (2003). Does civil society matter? Governance in contemporary India. New Delhi/Thousand Oaks/Londres, Sage Publications.

TEIXEIRA, Ana Claudia. (2002), "A atuação das organizações não-governamentais: entre o Estado e o conjunto da sociedade", in E. Dagnino (org.), Sociedade civile espaços públicos no Brasil, São Paulo, Paz e Terra.

URBINATI, Nadia. (2000), "Representation as advocacy: a study of democratic deliberation". Political Theory, 28 (6): 758-786.

WALZER, Mark (1992), "The civil society argument”, in C. Mouffe (ed.), Dimensions of radical democracy: pluralism, citizernship, community, Londres, Verso.
WARREN, Mark. (2004), "What kind of civil society is best for democracy? Portuguese Journal of Social Science, 3 (1).

WASSERMAN, S. \& FAUST, K. (1994), Social network analysis: methods and applications: structural analysis in the social sciences. Cambridge, Cambridge University Press, vol. 8. 


\section{ATORES PERIFÉRICOS \\ NA SOCIEDADE CIVIL: \\ REDES E CENTRALIDADES DE ORGANIZAÇÕES EM SÃO PAULO}

\author{
Adrián Gurza Lavalle, Graziela \\ Castello e Renata Mirandola Bichir
}

Palavras-chave: Análise de redes; Sociedade civil; São Paulo; Organizações civis periféricas.

A partir de análise de redes este artigo identifica os atores que ocupam posições periféricas na sociedade civil paulistana e analisa suas lógicas de atuação e suas estratégias relacionais ou de interação com outros atores. Os resultados, oriundos de survey aplicado a 202 organizações civis no município de São Paulo, mostram que associações comunitárias e associações de bairro guardam as posições mais periféricas, antecedidas por entidades assistenciais e fóruns, cuja centralidade é intermediária. Esses atores caracterizam-se pela sobreposição de desvantagens estruturais. Contudo, a análise revela que as entidades ocupam posições periféricas e intermediárias por motivos distintos e no cumprimento de vocações funcionais diferentes, bem como que elas lidam com sua condição periférica e intermediária de modo diferenciado, inclusive atenuando consideravelmente as limitações relacionais à sua capacidade atuação e decisão graças à construção seletiva de vínculos com entidades que ocupam posições altamente centrais. Assim, o artigo avança para além da mera constatação das hierarquias posicionais, alimentando elaborações nuançadas do modo de operação das entidades examinadas.

\section{PERIPHERAL ACTORS IN THE CIVIL SOCIETY: NETWORKS AND CENTRALITIES OF ORGANIZATIONS IN SÃO PAULO}

\author{
Adrián Gurza Lavalle, Graziela \\ Castello and Renata Mirandola \\ Bichir
}

Keywords: Network analysis; Civil society; São Paulo; Peripheral civil organizations.

Based on network analysis, this article identifies the actors in peripheral positions within São Paulo civil society and examines their different logics of performance and their relational or interactional strategies towards other actors. Findings of a survey with 202 civil organizations in the city of São Paulo show that community and neighborhood associations keep the most peripheral positions, preceded by service non-profits and forums, of middle centrality. Those actors are characterized by the superposition of structural disadvantages. However, this article shows that organizations occupy peripheral and middle centrality positions for distinct reasons and fulfill different functional vocations. It also shows that civil organizations deal with their peripheral and intermediate condition in different ways, even reducing considerably the relational constraints to their capacity for action and decision by establishing selective ties with organizations in highly central positions. Therefore, the article goes beyond the mere identification of positional hierarchies, developing nuanced formulations about the modus operandi of the organizations examined.

\section{ACTEURS PÉRIPHÉRIQUES DANS LA SOCIÉTÉ: RÉSEAUX ET CENTRALITÉS D'ORGANISATIONS À SÃO PAULO}

\author{
Adrián Gurza Lavalle, Graziela \\ Castello et Renata Mirandola Bichir
}

Mots-clés: Analyse de réseaux; Société civile; São Paulo; Organisations civiles périphériques.

Cet article identifie, à partir de l'analyse des réseaux, les acteurs qui occupent des positions périphériques dans la société civile de la ville de São Paulo et étudie ses logiques d'action et ses stratégies relationnelles ou d'interaction avec d'autres acteurs. Les résultats, issus de du sondage réalisé auprès de 202 organisations civiles dans la commune de São Paulo, ont démontré que les associations communautaires et les associations de quartier recèlent les points de vue les plus périphériques, précédés par des entités assistantielles et des forums dont la centralité est intermédiaire. Ces acteurs se caractérisent par la superposition de désavantages structuraux. Néanmoins, notre analyse révèle que les entités occupent des positions périphériques et intermédiaires par des motifs distincts et pour l'accomplissement de vocations fonctionnelles différentes. Elles travaillent avec leur condition périphérique et intermédiaire de façon différenciée, y compris en atténuant considérablement les limitations relationnelles à leur capacité d'action et de décision, grâce à une construction sélective de liens avec des entités qui occupent des positions hautement centrales. Cet article avance, ainsi, au-delà de la simple constatation des hiérarchies positionnelles, en alimentant des élaborations nuancées du mode d'opération des entités examinées. 